\author{
Marquette University \\ e-Publications@Marquette
}

7-2019

\title{
Elite Influence on Climate Change Skepticism: Evidence from Close Gubernatorial Elections
}

Andrew G. Meyer

Marquette University, andrew.meyer@marquette.edu

Follow this and additional works at: https://epublications.marquette.edu/econ_fac

Part of the Economics Commons

\section{Recommended Citation}

Meyer, Andrew G., "Elite Influence on Climate Change Skepticism: Evidence from Close Gubernatorial Elections" (2019). Economics Faculty Research and Publications. 609.

https://epublications.marquette.edu/econ_fac/609 
Marquette University

e-Publications@Marquette

\title{
Department of Economics Faculty Research and Publications/College of Business
}

This paper is NOT THE PUBLISHED VERSION.

Access the published version via the link in the citation below.

Journal of the Association of Environmental and Resource Economists, Vol. 6, No. 4 (2019, July): 783-

822. DOI. This article is (C) University of Chicago Press and permission has been granted for this version to appear in e-Publications@Marquette. University of Chicago Press does not grant permission for this article to be further copied/distributed or hosted elsewhere without express permission from University of Chicago Press.

\section{Elite Influence on Climate Change Skepticism: Evidence from Close Gubernatorial Elections}

\author{
Andrew G. Meyer \\ Department of Economics, Marquette University, Milwaukee, WI
}

\begin{abstract}
Many theorize that public opinion follows political elite on climate change skepticism, yet evidence of a causal link is lacking. I use a regression discontinuity design to establish the impact of the political party of a governor on constituents' global warming beliefs. I find that, relative to the election of a Democratic governor, the election of a Republican governor significantly decreases the probability of a Republican constituent believing in global warming by approximately 11-15 percentage points; there is no significant impact on Democratic constituents. I also find a negative effect of a Republican governor on belief in human-caused global warming that does not differ by constituent partisan affiliation. These results provide one explanation for the increased political polarization in global warming beliefs despite the scientific consensus. Belief formation often plays an important role in political economy models, so these findings also have implications for implementing climate change policy.
\end{abstract}


Recent polls reveal that a majority of US adults are concerned about climate change. ${ }^{1}$ For example, a March 2016 Gallup poll finds that 64\% of US adults say they are worried a "great deal" or "fair amount" about global warming (Gallup 2016) and a 2016 Pew Research Poll finds that 74\% of US adults care "a great deal" or "some" about the issue of global climate change (Pew Research Center 2016). Yet, there are substantial differences in climate change beliefs and concern across segments of US society; individual party affiliation is recognized as one of the particularly strong predictors of climate change beliefs (e.g., Borick and Rabe 2010; Hornsey et al. 2016; Egan and Mullin 2017). Moreover, research suggests that political polarization on climate change has increased over recent years (e.g., Dunlap and McCright 2008; McCright and Dunlap 2011). ${ }^{2}$ In contrast to the political polarization, there is a strong consensus in the scientific community that climate change is real. According to the Intergovernmental Panel on Climate Change (IPCC), climate change has caused widespread impacts on human and natural systems, continued greenhouse gas emissions will cause further warming and changes to the climate system, ${ }^{3}$ and limiting climate change risks would require substantial reductions in greenhouse gas emissions (IPCC 2014).

Why is it that political polarization on climate change has increased when the scientific consensus is clear? In this paper, I provide one potential explanation; climate change platforms and policies of the political elite impact the climate change beliefs of their constituents. Specifically, I find that party affiliation of political leaders differentially affects the climate change beliefs of individuals identifying with the Republican versus Democratic party. ${ }^{4}$ This finding is consistent with the Druckman et al. (2013) experimental evidence that elite partisan polarization-high levels of homogeneity within elected representatives of a party and high levels of ideological differences across elected representatives of parties-increases the impact of party endorsements on public opinion and lessens the importance of substantive information.

Economists have a long-standing interest in belief formation. ${ }^{5}$ Beliefs often play an important role in theoretical political economy models and can specifically impact chosen levels of environmental regulation (e.g., Yu 2005). Moreover, there are efficiency implications if political communication instills inaccurate beliefs in constituents. DellaVigna and Gentzkow $(2010,644)$ argue that "the efficiency of market economies and democratic political systems depends on the accuracy of individuals' beliefs." ${ }^{6}$ Voters will be ill equipped to judge climate change policies if their beliefs contradict the scientific evidence. As framed by Millner and Ollivier (2016, 226), "the beliefs of the general public are 'ground zero' for the battle to implement environmental policies." Furthermore, "the process of social belief formation, and its consequences for the political economy of environmental policy, should be an integral part of the positive study of environmental regulation" (Millner and Ollivier 2016, 227). Economists should therefore care about public opinion on climate change because, despite the economic arguments in favor of climate change policy, it may be difficult to enact policy against the headwind of public opposition.

Estimating the impact of political elite opinion on mass opinion is empirically challenging. Absent a credible identification strategy, we would be concerned about endogeneity because areas that vote for Republican representatives could be quite different along many unmeasured dimensions as compared to areas that vote for Democratic representatives. I circumvent these endogeneity concerns by 
leveraging close gubernatorial election outcomes to identify how the governor's political party affects mass opinion. The regression discontinuity design (RDD) estimates the causal effect of a Republican gubernatorial win on the probability that a constituent believes there is solid evidence of global warming, relative to the counterfactual of a Democratic gubernatorial win. This identification strategy originates with Lee $(2001,2008)$ and has been utilized elsewhere in the literature to determine the causal impact of elections (e.g., Leigh 2008; Beland 2015; Doyle et al. 2016). The intuition is that, if the political party of the winning candidate has no bearing on constituent global warming beliefs, then constituent global warming beliefs should not change discontinuously at the threshold between gubernatorial races that narrowly had Republican winners versus those that narrowly had Democrat winners.

I match multiple waves of the National Surveys on Energy and Environment (NSEE) from 2008 to 2015 with gubernatorial election results to generate a sample of US individuals from all 50 states. I first estimate local linear regressions with bias correction and optimal bandwidth, as suggested by de la Cuesta and Imai (2016), Gelman and Imbens (2017), and Skovron and Titiunik (2015). When using the overall sample, I find consistent negative point estimates for the effect of a Republican gubernatorial win on global warming beliefs of constituents, but the estimates are not statistically significant. However, I do find evidence of significant heterogeneity in the treatment effect; a Republican gubernatorial win significantly decreases the probability of a Republican constituent believing in global warming by approximately 11-15 percentage points whereas there is no significant effect of a Republican win on the global warming beliefs of Democrat constituents. ${ }^{7}$ I then use several specifications to formally test for differential effects on constituents of different party affiliations. Here, I confirm that the effect of a Republican gubernatorial win on climate change beliefs is significantly stronger for Republican constituents than for Democratic constituents. In the preferred specification, Republican individuals are approximately 11 percentage points less likely to believe in climate change relative to Democratic individuals when a Republican candidate wins a close gubernatorial election. However, on the issue of anthropogenic climate change, I find a negative and significant treatment effect for the overall population; the effect of a Republican gubernatorial win on human-caused global warming beliefs does not differ by political identification of the respondent.

I make several important contributions with this paper. While some have theorized that the public follows the lead of the political elite on climate change, Egan and Mullin $(2017,220)$ note that "scholars have not identified a direct causal link between climate change skepticism campaigns and individual attitudes." ${ }^{8}$ Thus, the most important contribution is that I provide causal evidence that the climate change stance of a political leader impacts climate change beliefs of constituents. This finding has important implications for how climate change skepticism could persist into the future despite the scientific evidence. A second contribution is that I provide new quasi-experimental evidence that political communication impacts opinion in general. Many earlier papers find a strong correlation between political communication and opinion. However, with some exceptions, most of the extant empirical evidence lacks credible identification strategies and should thus be interpreted as correlational (Gabel and Scheve 2007; DellaVigna and Gentzkow 2010). ${ }^{9}$ A third contribution is to the growing literature on the impacts of political ideology; there is growing evidence that political ideology affects the extent of one's pro-environmental behavior. ${ }^{10}$ 
There is a political divide among elected representatives along partisan lines with regard to environmental issues. ${ }^{11}$ Republican governors typically deny climate change while Democratic governors accept the science of climate change. A 2014 report categorizes the nation's governors into four groups according to their climate change beliefs (Koronowski 2014). At the time of the report, only Democrats were labeled as "green" for proactively implementing climate change policies. Moreover, "fifteen out of twenty nine sitting Republican governors openly deny climate science" (Koronowski 2014). That is, over half of Republican governors in 2014 were categorized as "climate deniers." In contrast, "None of the country's Democratic governors have made public statements denying climate change" (Koronowski 2014). While there are several exceptions during the sample period, almost all Republican governors either deny climate change or remain silent on the issue. ${ }^{12}$

Given the partisan divide in climate change positions of the political elite, there must be a plausible transmission mechanism to claim that I identify the impact of political elite on constituents' climate change beliefs. More generally, there is theory and evidence that political communication influences individuals' political opinions. When confronted with a complex issue such as climate change, individuals tend to look for cues from the political elite to form an opinion. ${ }^{13}$ Rugeley and Gerlach (2012) argue that individuals adopt the climate change positions of political elite to mitigate informational costs of understanding complex scientific issues. As summarized by Egan and Mullin $(2017,217)$, "the complex scientific content on the climate change issue can make it difficult for individuals to form their own judgments about the accuracy of climate science or the potential impacts of climate policy, leading most to look to partisan elites for information about the quality of evidence and the likely effects of policy proposals."

Although the literature on elite leadership of public opinion has not focused much on governors, previous literature does suggest that a governor's stance on an environmental issue could matter. Research dating to Hinckley et al. (1974) shows that voters are quite familiar with gubernatorial candidates. Squire and Fastnow (1994) show that governors get more media coverage than US senators and voters are more familiar with governors than US senators: "Indeed, it is likely that among elected officials, only the president and vice president are better known than the governor" (Squire and Fastnow 1994, 708). Atkeson and Partin (2001) find that, relative to US senators, governors focus more on developmental concerns such as the environment. Furthermore, previous research shows that simply adopting positions can be enough to sway voters' opinions (Broockman and Butler 2017). So, governors' positions on the environment and climate change could influence public opinion, even if governors are not regularly engaging in active debate about climate change.

Moreover, there is reason to expect that the political opinion impact may be moderated by the political affiliation of the constituent. Studies show that education and scientific knowledge positively correlate with belief in climate change for Democrats but have weak or even negative correlation for Republicans (Malka et al. 2009; McCright and Dunlap 2011; Guber 2013; Kahan 2015; Egan and Mullin 2017). The implication is that providing scientific information about climate change may have differential effects on Democrats and Republicans. Also, multiple studies find evidence of partisan contrasts in the effectiveness of communicating with different frames, with frames typically having larger impact for Republican opinion than for Democrat opinion (Hardisty et al. 2010; Gromet et 
al. 2013; Egan and Mullin 2017). Thus, prior evidence provides reasons why Republicans could be more susceptible to persuasion from political elite on the issue of climate change.

\section{Data}

This study requires merging survey responses on global warming beliefs with gubernatorial election information. Consistent with Beland (2015), I obtain gubernatorial election results from Leip's Atlas of US Presidential Elections (2017). I include all elections from all 50 states where either a Democrat or a Republican won; elections with an Independent winner are not included. Apart from New Hampshire and Vermont, ${ }^{14}$ governors serve 4 -year terms. ${ }^{15}$ Gubernatorial elections typically take place in November with the winner taking office in January. Therefore, I link the election results from November of year $t$ with global warming beliefs from individuals in that state from years $t+1$ to $t+$ 4. ${ }^{16}$ Governors sometimes leave office early for a variety of reasons. If their replacement takes power without an election and is of the same political party, I keep the corresponding observations in the sample. However, in the rare case that the replacement belongs to a different party, the corresponding observations are excluded from analysis. If there is a special election to determine the replacement, I use the results of the special election for the remainder of the term until the next election.

Data on individuals and their global warming beliefs come from multiple waves of the National Surveys on Energy and Environment (NSEE). The NSEE include twice per year national opinion surveys on issues related to energy, the environment, and climate change. The NSEE are a collaborative effort between the Muhlenberg Institute of Public Opinion at Muhlenberg College and the Center for Local, State, and Urban Policy (CLOSUP) at the University of Michigan's Gerald R. Ford School of Public Policy. Published in July 2017, version 12 of the NSEE project covers the time period of 9/2/2008 to 9/24/2015 (Rabe and Borick 2017). ${ }^{17}$ Each of the 14 waves contain data on approximately $600-900$ respondents; $87.5 \%$ of respondents provide an answer to the survey question about global warming beliefs, and $90.6 \%$ of respondents provide an answer to the survey question about political affiliation. Each wave of the NSEE surveys ask respondents, "Which of the following best describes your political party affiliation?" The options are: Democrat, Republican, Other Party, Independent, or Not Sure. Counting only individuals who provide their global warming beliefs, have a Democratic or Republican governor, and report their individual political affiliation, there are 8,756 observations from all 50 states. ${ }^{18} \mathrm{~A}$ small number of individuals do not report race/ethnicity and are excluded from the main sample. ${ }^{19}$ As such, the main sample for analysis contains 8,680 observations.

Table 1 provides summary statistics for the main sample and for the US population as a comparison. As seen in Table 1, all demographic groups are represented in the NSEE. However, the sample contains a relatively higher proportion of white/Caucasian respondents and relatively lower proportions of racial/ethnic minorities, as compared to the US population. ${ }^{20}$ As such, I control for race/ethnicity in the regressions of section 2. Also, the NSEE sample is older and more highly educated than the US population at large; I therefore show specifications where I control for age and education.

Table 1. Descriptive Statistics for the NSEE

\begin{tabular}{|l|l|l|}
\hline Variable & Sample Mean & US Population \\
\hline Global warming belief & .709 & NA \\
\hline Race/ethnicity: & & \\
\hline
\end{tabular}




\begin{tabular}{|l|l|l|}
\hline White/Caucasian & .814 & .769 \\
\hline African American & .0749 & .133 \\
\hline Asian & .0262 & .057 \\
\hline Hispanic/Latino & .0469 & .178 \\
\hline Mixed race and other & .0381 & .039 \\
\hline Male & .482 & .492 \\
\hline College educated & .485 & .303 \\
\hline Age 45 or older & .695 & .534 \\
\hline Governor political affiliation: & & \\
\hline Democrat & .47 & $\mathrm{NA}$ \\
\hline Republican & .53 & $\mathrm{NA}$ \\
\hline Individual political affiliation: & & \\
\hline Democrat & .385 & .29 \\
\hline Republican & .296 & .26 \\
\hline Independent & .319 & .42 \\
\hline Global warming belief by individual political affiliation: & & \\
\hline Democrat & .853 & $\mathrm{NA}$ \\
\hline Republican & .52 & $\mathrm{NA}$ \\
\hline Independent & .711 & $\mathrm{NA}$ \\
\hline
\end{tabular}

Note. Sample means are from author's calculations. US population statistics are from the US census (2016). NSEE = National Surveys on Energy and Environment.

The exact wording of the global warming belief question is "From what you've read and heard, is there solid evidence that the average temperature on earth has been getting warmer over the past four decades?" (Rabe and Borick 2017). Approximately $71 \%$ of the sample answer "yes" to this question. There is an apparent correlation between global warming belief and individual political affiliation. As shown in Table 1, over $85 \%$ of Democrats believe in global warming, around $71 \%$ of Independents believe in global warming, and $52 \%$ of Republicans believe in global warming.

\section{Empirical Strategy and Results}

This paper seeks to identify the impact of a governor's political party on the global warming beliefs of constituents. Gubernatorial election outcomes are potentially endogenous to global warming beliefs. There are many unobserved characteristics of gubernatorial candidates and states, correlated with election outcomes, that also affect constituent behavior and beliefs. Thus, I adopt the RDD identification strategy, which uses outcomes of close elections as a quasi-experiment. The use of the RDD for identification of the effects of election outcomes stems from Lee $(2001,2008)$ and has been applied in papers such as Lee et al. (2004), Petterson-Lidbom (2008), and Ferreira and Gyorko (2009). Beland (2015), Beland and Boucher (2015), Beland and Oloomi (2017), Beland and Unel (2018), and Leigh (2008) utilize the RDD specifically in the context of gubernatorial elections. Before presenting regression results, I first provide some graphical evidence of the discontinuity. 


\subsection{Graphical Evidence}

Define the margin of victory as the difference between the election vote share received by the Republican and Democratic candidates. Then, a positive margin of victory signifies that the Republican candidate won the election and the RDD threshold is defined where the margin of victory for a Republican governor is $0 \%$. Figure 1 shows RD plots for the probability that a respondent believes in global warming. Each plotted point represents the proportion of individuals who believe in global warming within each margin of victory bin. Figure 1A-1D fits linear functions on both sides of the RD threshold using only data from elections within the Calonico et al. (2018) optimal bandwidth and thus provides a graphical representation of the local linear regressions reported in the next subsection, 2.2. ${ }^{21}$ Panel $A$ includes all respondents, panel $B$ includes only self-identified Democratic respondents, panel $C$ includes only self-identified Republican respondents, and panel $D$ includes only Independent respondents.
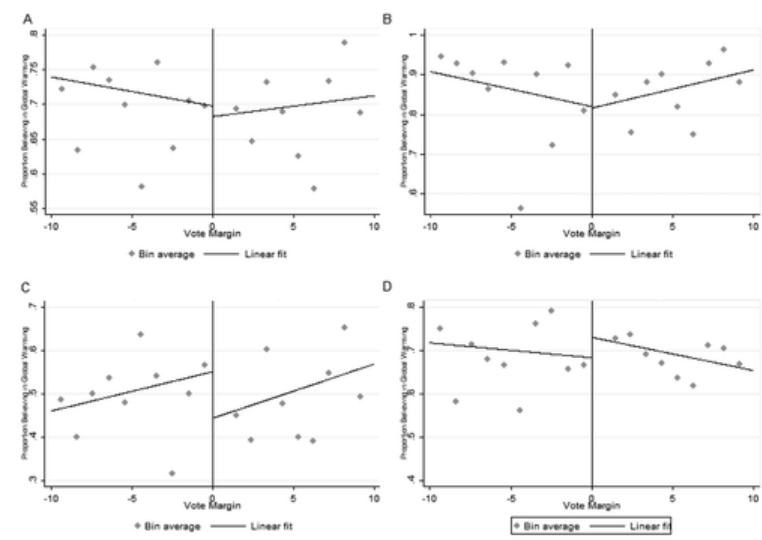

Figure 1. RD plot of vote margin versus global warming beliefs: optimal bandwidth. Positive vote margin indicates Republican governor. All respondents are included in panel $A$. Only Democrat respondents are in panel $B$. Only Republican respondents are in panel $C$. Only Independent respondents are in panel $D$.

In figure $1 \mathrm{~A}$, there is a small discontinuity in the proportion of respondents believing in climate change when crossing the RD threshold. Visually, a Republican win decreases the probability of a respondent believing in global warming by approximately 2 percentage points for this overall sample. Figure $1 \mathrm{~B}$ shows that there is little change in the probability of a self-identified Democrat respondent believing in global warming when a Republican governor wins. Figure $1 \mathrm{C}$ indicates that there is a larger drop in the probability of a self-identified Republican respondent believing in global warming when a Republican governor wins a close election; the magnitude of the discontinuity at the RD threshold is approximately 10 percentage points.

Figure $1 \mathrm{C}$ exhibits visual decreases in the bin averages just to the right of the threshold (close Republican wins) versus those just to the left of the threshold (close Democratic wins), so it is worth describing the states and individuals represented in these bins. ${ }^{22}$ States from various geographic regions (East vs. West, North vs. South, etc.) are represented in these closest elections. Also, multiple states appear in the sample as both close Democratic wins and close Republican wins. Table A1 reports on tests for differences in proportion of male, college educated, white, older, conservative, Republican, Democrat, and Independent respondents for individuals just below the threshold ( $6 \leq$ vote margin < $0)$ versus individuals just above the threshold $(0<$ vote margin $\leq 6)$. I do not find any significant 
differences in the proportions of individuals holding these characteristics based on treatment status. Therefore, individuals represented in the states having close vote margins appear similar on observable characteristics, suggesting that they are likely to also be similar on unobservable characteristics. As emphasized by de la Cuesta and Imai (2016) and Skovron and Titiunik (2015), the continuity assumption-necessary for the RD design in this paper-does not require covariate balance based on treatment status. It only requires that the expected potential outcome does not discontinuously jump at the threshold. Thus, the covariate balance seen in Table A1 lends additional credibility to the design but is not required for identification. ${ }^{23}$

Finally, figure 1D shows a smaller increase in the probability of a self-identified Independent respondent believing in global warming when a Republican governor wins a close election. The magnitude of the increase is about 4.5 percentage points for Independent respondents. While these plots of the raw data are informative, I next present estimates from regressions that condition on several baseline covariates and facilitate inference on the RD treatment effects of interest.

\subsection{Local Linear Regressions with Bias Correction}

The RD treatment effect is the difference between the expected proportion of respondents believing in global warming given a Republican election win and the expected proportion of respondents believing in global warming given a Democratic election win at the RD threshold $\left(v m_{0}\right)$. However, since there are no treatment or control observations exactly at $v m_{0}$, one must use observations close to $v m_{0}$ for estimation. The first step of local linear estimation is therefore to choose the bandwidth, $h$, for estimation; only observations within this bandwidth are used to fit linear regression functions on both sides of the threshold. As recommended in the literature, I use an optimal bandwidth that minimizes the mean squared error (MSE) of the local linear estimator (Imbens and Kalyanaraman 2012; Calonico et al. 2014b; Skovron and Titiunik 2015; de la Cuesta and Imai 2016; Gelman and Imbens 2017). As is standard, I primarily utilize a triangular kernel, ${ }^{24}$ which weights observations closer to the RD threshold more heavily. Because the nonparametric local polynomial approach approximates an unknown functional form near the threshold, there is a bias that arises in the estimator. ${ }^{25} \mathrm{~A}$ bias-correction procedure estimates the bias term and subtracts it from the RD point estimate. Calonico et al. (2014a, 2014b) provide methods to conduct inference on RD estimates that account for the bias term. Therefore, as recommended by de la Cuesta and Imai (2016), and Skovron and Titiunik (2015), I show results using the robust inference of Calonico et al. (2018) for all bias-corrected estimates. ${ }^{26}$ For completeness and transparency, I also show conventional (not bias-corrected) parametric point estimates with standard errors clustered at the state level (conventional RD inference). ${ }^{27}$ Hereafter, I refer to the bandwidth and estimation procedures of Calonico et al. (2018) as "Calonico et al."

Table 2 presents the baseline RD results. ${ }^{28}$ Each of these columns include survey year fixed effects to improve precision. Columns 2, 4, and 6 also include the baseline covariates of race/ethnicity and gender. The first two columns show results for the full sample. While the point estimates suggest that Republican governors decrease the probability of a respondent believing in global warming, the estimates are not significant at conventional levels. Likewise, I do not find statistical evidence of a Republican governor impacting the global warming beliefs of Democratic respondents in columns 3 and 4. However, when limiting the sample to Republican respondents only in columns 5 and 6, I find large and statistically significant effects. The preferred bias-corrected estimate in column 6 indicates 
that, relative to the counterfactual of a Democratic governor, a Republican governor decreases the probability of a Republican respondent believing in global warming by approximately 14.5 percentage points.

Table 2. Baseline Local Linear RD Results: Global Warming Is Real

\begin{tabular}{|l|l|l|l|l|l|l|}
\hline & $\begin{array}{l}\text { Full } \\
\text { Sample }\end{array}$ & & $\begin{array}{l}\text { Democrat } \\
\text { Respondents }\end{array}$ & $\begin{array}{l}\text { Republican } \\
\text { Respondents }\end{array}$ & \\
\hline & $\mathbf{( 1 )}$ & $\mathbf{( 2 )}$ & $\mathbf{( 3 )}$ & $\mathbf{( 4 )}$ & $\mathbf{( 5 )}$ & $\mathbf{( 6 )}$ \\
\hline Conventional & -.0208 & -.0242 & -.0268 & -.0246 & $-.114^{* *}$ & $-.128^{* * *}$ \\
\hline $\begin{array}{l}\text { Bias corrected } \\
\text { robust }\end{array}$ & $-.0189)$ & $(.0184)$ & $(.0398)$ & $(.0398)$ & $(.0487)$ & $(.0455)$ \\
\hline & -.0212 & -.0259 & -.0242 & $-.131^{* *}$ & $-.145^{* * *}$ \\
\hline $\begin{array}{l}\text { Race/ethnicity and } \\
\text { gender }\end{array}$ & $(.0229)$ & $(.0222)$ & $(.0464)$ & $(.0463)$ & $(.0580)$ & $(.0558)$ \\
\hline BW estimation & 8.620 & $\mathrm{X}$ & & $\mathrm{X}$ & & $\mathrm{X}$ \\
\hline BW bias & 18.267 & 17.992 & 16.456 & 16.596 & 18.345 & 20.255 \\
\hline Observations & 8,680 & 8,680 & 3,342 & 3,342 & 2,573 & 2,573 \\
\hline $\begin{array}{l}\text { Effective } \\
\text { observations }\end{array}$ & 2.769 & 2,759 & 1,214 & 1,174 & 923 & 959 \\
\hline
\end{tabular}

Note. Standard errors are in parentheses. Standard errors for conventional RD (regression discontinuity) estimates are clustered at the state level. Standard errors for bias corrected RD estimates are Calonico et al.robust, clustered at the state level. All specifications include year fixed effects and use the triangular kernel. "Effective observations" refers to the number of observations within the estimation bandwidth (BW).

$*_{p}<.1$.

$* * p<.05$.

$* * * p<.01$.

\subsection{RD Specifications on the Pooled Data to Test for Differential Effects}

I next present results from parametric RD specifications on the pooled data because these specifications facilitate straightforward hypothesis testing for differences between groups. In the present context, one can easily test whether the discontinuity differs for Democrat versus Republican respondents. Also, these specifications facilitate the inclusion of additional baseline covariates such as state fixed effects; this can reduce the residual variance and produce more precise estimates.

Denote the vote margin in state $s$ in year $t$ as $\mathrm{VM}_{s t}$, where positive values indicate the election of a Republican governor and negative values indicate the election of a Democratic governor. The discontinuity therefore occurs at VMst=0VMst=0. The baseline RD specification is

$$
\begin{aligned}
\mathrm{GW}_{i s t}= & \beta_{0}+\beta_{1} \mathrm{RG}_{s t}+\beta_{2} \mathrm{RP}_{i s t}+\beta_{3} \mathrm{RG}_{s t} \cdot \mathrm{RP}_{i s t}+\beta_{4} \mathrm{IP}_{i s t}+\beta_{5} \mathrm{RG}_{s t} \cdot \mathrm{IP}_{i s t}+\beta_{6} X_{i s t} \\
& +f\left(\mathrm{VM}_{s t}\right)+f\left(\mathrm{VM}_{s t}\right) \cdot \mathrm{RP}_{i s t}+f\left(\mathrm{VM}_{s t}\right) \cdot \mathrm{IP}_{i s t}+\psi_{t}+\zeta_{s}+\varepsilon_{i s t}
\end{aligned}
$$

The outcome variable, $\mathrm{GW}_{\text {ist }}$, is an indicator for belief in global warming. The variable $\mathrm{RG}_{s t}$ is an indicator for a Republican governor holding office in state $s$ in year $t, \mathrm{RP}_{\text {ist }}$ is an indicator for an individual $i$ residing in state $s$ in year $t$ who reports a Republican party affiliation, $I \mathrm{P}_{\text {ist }}$ is an indicator for 
an individual who self-reports as Independent in their party affiliation, $X_{\text {ist }}$ includes individual characteristics such as race/ethnicity and gender, $\psi_{t}$ are year fixed effects, and $\zeta_{s}$ are state fixed effects. The continuous relationship between vote margin and global warming belief is captured with $f\left(\mathrm{VM}_{s t}\right)$, which is a linear function of vote margin (allowed to take on different slopes on each side of the discontinuity). The linear function of vote margin is also interacted with the individual-level political affiliation variables to allow for different trends based on self-identified political affiliation. The coefficients $\beta_{1}, \beta_{3}$, and $\beta_{5}$ are the main parameters of interest, as they represent the differential effects of a Republican governor on the global warming beliefs of individuals of different party affiliations. Note that, because all individuals in the sample self-report a political affiliation of Democrat, Republican, or Independent, $\beta_{1}$ represents the impact of a Republican governor on the global warming beliefs of a Democratic individual. Coefficient $\beta_{3}$ represents the differential effect of a Republican governor on the global warming beliefs of a Republican individual, relative to a Democratic individual. Likewise, $\beta_{5}$ represents the differential effect of a Republican governor on the global warming beliefs of an Independent individual, relative to a Democratic individual. Therefore, the overall effect of a Republican governor on the global warming beliefs of a Republican individual is $\beta_{1}+$ $\beta_{3}$, and the overall effect of a Republican governor on the global warming beliefs of an Independent individual is $\beta_{1}+\beta_{5}$.

As a baseline in Table 3, I use linear controls and the Calonico et al. optimal bandwidth. ${ }^{29}$ I do not find any evidence across specifications that the election of a Republican governor affects the global warming beliefs of Democratic constituents. However, consistent with the bias-corrected results on the partisan subsamples from section 2.2, I do find evidence that the election of a Republican governor has a differential effect on Republican constituents. The preferred specification (1) with state fixed effects, year fixed effects, race/ethnicity controls, and gender controls indicates that the election of a Republican governor decreases the probability of a Republican constituent believing in global warming by approximately 11 percentage points, relative to a Democrat constituent. The overall impact of a Republican governor on Republican constituents is an approximate 8.5 percentage point drop in the probability of global warming belief. Columns $2-4$ show that this differential effect is not sensitive to the chosen baseline covariates and fixed effects.

Table 3. RD Specifications for Differential Effects: Global Warming Is Real

\begin{tabular}{|l|l|l|l|l|}
\hline & $(\mathbf{1})$ & $\mathbf{( 2 )}$ & $\mathbf{( 3 )}$ & $\mathbf{( 4 )}$ \\
\hline Republican Governor (RG) & .0274 & .00698 & .0247 & .0117 \\
\hline & $p=.454$ & $p=.886$ & $p=.516$ & $p=.786$ \\
\hline RG $\times$ Rep. Individual & $-.113^{* * *}$ & $-.100^{* *}$ & $-.0969^{* * *}$ & $-.0983^{* *}$ \\
\hline & $p=.004$ & $p=.022$ & $p=.010$ & $p=.032$ \\
\hline RG $\times$ Ind. Individual & .0129 & .0342 & .00194 & .0246 \\
\hline & $p=.788$ & $p=.57$ & $p=.956$ & $p=.662$ \\
\hline Rep. Individual & $-.263^{* * *}$ & $-.268^{* * *}$ & $-.266^{* * *}$ & $-.268^{* * *}$ \\
\hline & $p=.002$ & $p=.002$ & $p=.002$ & $p=.002$ \\
\hline Ind. Individual & $-.125^{* * *}$ & $-.133^{* * *}$ & $-.119^{* * *}$ & $-.127^{* * *}$ \\
\hline & $p=.002$ & $p=.002$ & $p=.002$ & $p=.002$ \\
\hline Male & $-.0387^{* *}$ & $-.0423^{* *}$ & $-.0443^{* *}$ &. \\
\hline & $p=.014$ & $p=.014$ & $p=.012$ &. \\
\hline & & & & \\
\hline
\end{tabular}




\begin{tabular}{|l|l|l|l|l|}
\hline State fixed effects & X & & $X$ & \\
\hline Year fixed effects & X & & $X$ & \\
\hline Race/ethnicity and gender & $\mathrm{X}$ & $\mathrm{X}$ & $\mathrm{X}$ & \\
\hline Additional controls & & & $\mathrm{X}$ & \\
\hline Observations & 3,512 & 3,512 & 3,462 & 3,512 \\
\hline No. of clusters (states) & 34 & 34 & 34 & 34 \\
\hline
\end{tabular}

Note. $p$-values are generated using the wild bootstrap procedure from Cameron et al. (2008). Clustering is at the state level. All specifications include linear controls and use the optimal bandwidth of 10.051 .

$* p<.1$.

$* * p<.05$.

$* * * p<.01$.

While not the focus of this paper, I note that individuals reporting Republican partisan affiliation have a substantially lower baseline probability of believing in global warming relative to Democratic individuals. A Republican survey respondent is 26.3 percentage points less likely to believe in global warming as compared to Democratic respondents. For reference, the unconditional probability of a Democratic individual in the sample believing in global warming is 0.853 . Thus, the election of a Republican governor serves to further decrease the likelihood of global warming belief among a subgroup that already has a significantly lower baseline probability of believing.

\subsection{Validity Checks and Falsification Tests}

Several papers have called into question the appropriateness of the RDD in the context of close elections (Snyder 2005; Caughey and Sekhon 2011; Grimmer et al. 2011). However, another set of papers argue that the assumptions behind the RDD are likely met in most close election settings and provide recommendations for researchers applying the method (Eggers et al. 2015; Skovron and Titiunik 2015; de la Cuesta and Imai 2016). Here, I conduct the validity checks and falsification tests recommended by these papers.

First, as suggested by de la Cuesta and Imai (2016), I estimate local linear regressions where I replace the dependent variable of global warming belief with other baseline covariates that should not change discontinuously at the threshold. Table 4 reports these falsification tests for the baseline covariates of white/Caucasian, age 45 or older, male, and college educated. I use the optimal bandwidth calculation from Calonico et al. for each falsification test. ${ }^{30}$ As seen in Table 4, I do not find evidence of discontinuous changes in any of the predetermined covariates at the threshold; this supports the validity of the RD design. ${ }^{31}$

Table 4. Falsification Tests: Local Linear RD

\begin{tabular}{|l|l|l|l|l|}
\hline Outcome & $\begin{array}{l}\text { White } \\
\text { (1) }\end{array}$ & $\begin{array}{l}\text { Age 45 or Older } \\
\text { (2) }\end{array}$ & $\begin{array}{l}\text { Male } \\
\text { (3) }\end{array}$ & $\begin{array}{l}\text { College } \\
\text { (4) }\end{array}$ \\
\hline Conventional & -.00708 & .0165 & -.0386 & .0321 \\
\hline & $(.0535)$ & $(.0302)$ & $(.0319)$ & $(.0388)$ \\
\hline Bias corrected robust & -.00614 & .0236 & -.0473 & .0451 \\
\hline
\end{tabular}




\begin{tabular}{|l|l|l|l|l|}
\hline Outcome & $\begin{array}{l}\text { White } \\
(\mathbf{1})\end{array}$ & $\begin{array}{l}\text { Age 45 or Older } \\
(\mathbf{2})\end{array}$ & $\begin{array}{l}\text { Male } \\
(\mathbf{3})\end{array}$ & $\begin{array}{l}\text { College } \\
(\mathbf{4})\end{array}$ \\
\hline & $(.0612)$ & $(.0316)$ & $(.0366)$ & $(.0417)$ \\
\hline BW estimation & 10.479 & 8.724 & 10.825 & 11.008 \\
\hline BW bias & 17.188 & 19.806 & 18.166 & 22.920 \\
\hline Observations & 8,680 & 8,603 & 8,680 & 8,664 \\
\hline Effective observations & 3,585 & 2,739 & 3,676 & 3,669 \\
\hline
\end{tabular}

Note. Standard errors are in parentheses. Standard errors for conventional RD estimates are clustered at the state level. Standard errors for bias-corrected RD estimates are Calonico et al.-robust, clustered at the state level. All specifications include year fixed effects and use the triangular kernel. "Effective observations" refers to the number of observations within the estimation bandwidth (BW).

$* p<.1$.

$* * p<.05$.

$* * * p<.01$.

The null results on the local linear regressions reported in Table 4 show that there are no discontinuous changes in baseline covariates for the overall sample. However, the main result in this paper concerns differential effects for Republican versus Democratic individuals when a Republican governor is elected. Therefore, I also conduct falsification tests using the specification given in equation (1) (replacing global warming belief with the baseline covariates). As shown in Table 5, I do not find significant estimates for the coefficients on Republican Governor $\left(\beta_{1}\right)$ or Republican Governor $x$ Independent Individual $\left(\beta_{5}\right) .{ }^{32}$ I do find one significant coefficient on Republican Governor $x$ Republican Individual $\left(\beta_{3}\right)$ when using male gender as the outcome variable. However, the sign on the coefficient indicates that a Republican individual is less likely to be male (more likely to be female) when a Republican governor wins relative to when a Democratic governor wins. But females are more likely to believe in climate change as compared to males, ${ }^{33}$ so this placebo finding would tend to work in the opposite direction than the main result on the paper. That is, if anything, the estimated effect of a Republican governor on climate change beliefs of Republican individuals would be biased toward 0 due to this differential gender placebo effect. In summary, there is little evidence that baseline covariates change differentially at the RD threshold based on individual political affiliation, again adding credibility to the RD design.

Table 5. Falsification Tests: RD Specifications for Differential Effects

\begin{tabular}{|l|l|l|l|l|}
\hline Outcome & $\begin{array}{l}\text { White } \\
(\mathbf{1})\end{array}$ & $\begin{array}{l}\text { Age 45 or Older } \\
(\mathbf{2})\end{array}$ & $\begin{array}{l}\text { Male } \\
\mathbf{( 3 )}\end{array}$ & $\begin{array}{l}\text { College } \\
(\mathbf{4})\end{array}$ \\
\hline Republican Governor (RG) & .0149 & -.0522 & -.0457 & .0572 \\
\hline & $p=.898$ & $p=.376$ & $p=.478$ & $p=.366$ \\
\hline RG $\times$ Rep. Individual & .0314 & .0683 & $-.0729 *$ & .0889 \\
\hline & $p=.704$ & $p=.428$ & $p=.056$ & $p=.356$ \\
\hline RG $\times$ Ind. Individual & -.0413 & .00322 & .0769 & .0330 \\
\hline & $p=.546$ & $p=.98$ & $p=.404$ & $p=.686$ \\
\hline
\end{tabular}




\begin{tabular}{|l|l|l|l|l|}
\hline Outcome & $\begin{array}{l}\text { White } \\
\text { (1) }\end{array}$ & $\begin{array}{l}\text { Age 45 or Older } \\
\text { (2) }\end{array}$ & $\begin{array}{l}\text { Male } \\
\text { (3) }\end{array}$ & $\begin{array}{l}\text { College } \\
\text { (4) }\end{array}$ \\
\hline Order polynomial controls & 1 & 1 & 1 & 1 \\
\hline BW & 8.691 & 9.515 & 10.354 & 8.771 \\
\hline Optimal BW & $\mathrm{X}$ & $\mathrm{X}$ & $\mathrm{X}$ & $\mathrm{X}$ \\
\hline Observations & 2,769 & 3,169 & 3,543 & 2,763 \\
\hline No. of clusters (states) & 31 & 33 & 34 & 31 \\
\hline
\end{tabular}

Note. $p$-values are generated using the wild bootstrap procedure from Cameron et al. (2008). Clustering is at the state level. All specifications include controls for race/ethnicity and gender, individual partisan affiliation, state fixed effects, and year fixed effects.

$* p<.1$.

$* * p<.05$.

$* * * p<.01$.

The main potential threat to identification is that partisan affiliation is not exogenous. For example, the election of a Republican governor could cause a realignment of individual partisan affiliation based upon climate change beliefs. Previously Republican individuals who were believers in climate change could reidentify as Independent and previously Independent individuals who were climate skeptics could reidentify as Republican. I address this concern in four ways. First, I use the NSEE data to thoroughly test for any discontinuities in partisan identification. Second, I leverage repeated crosssectional data from the Cooperative Congressional Election Survey (CCES) to conduct a parallel test for a discontinuous shift in partisan affiliation. Third, I use within-individual variation in a panel from CCES to test whether individuals' partisan identification changes based upon the party of their governor. Finally, I analyze a subgroup of CCES individuals who initially reported a Republican affiliation in 2010 to see if defections from the Republican party are systematically related to the interaction of climate change beliefs and the party of the governor.

Table 6 shows the results of local linear regressions where indicators for partisan affiliation are the dependent variables. Columns 1 and 2 test for a discontinuous shift to Republican affiliation, columns 3 and 4 repeat the analysis for Democratic affiliation, and columns 5 and 6 show results for Independent affiliation. ${ }^{34}$ I do not find any evidence that the election of a Republican governor discontinuously affects the partisan affiliation of constituents. Because the optimal bandwidth in columns 1 and 2 for the outcome of Republican affiliation is smaller than the bandwidths used in the main analysis of this paper, I repeat the exercise in table OA3 using larger bandwidths. ${ }^{35}$ Again, I find no evidence that the election of a Republican governor discontinuously causes individuals to shift toward or away from a Republican identification. Finally, I look for heterogeneous impacts on partisan affiliation based on education in columns 4-7 of table OA3. The concern here is that more highly educated individuals tend to believe more in climate change as compared to less educated individuals; a heterogeneous impact on partisan identification based on education could drive the main results of the paper. However, I do not find evidence that a Republican governor discontinuously shifts partisan affiliation for less educated or for more highly educated individuals. ${ }^{36}$ 
Table 6. Falsification Tests for Partisan Identification: Local Linear RD

\begin{tabular}{|l|l|l|l|l|l|l|}
\hline Outcome & $\begin{array}{l}\text { Rep. } \\
(\mathbf{1})\end{array}$ & $\begin{array}{l}\text { Rep. } \\
(\mathbf{2})\end{array}$ & $\begin{array}{l}\text { Dem. } \\
\mathbf{( 3 )}\end{array}$ & $\begin{array}{l}\text { Dem. } \\
\mathbf{( 4 )}\end{array}$ & $\begin{array}{l}\text { Ind. } \\
\mathbf{( 5 )}\end{array}$ & $\begin{array}{l}\text { Ind. } \\
\mathbf{( 6 )}\end{array}$ \\
\hline Conventional & .00337 & -.0136 & -.00544 & .0074 & -.0103 & -.00558 \\
\hline & $(.0344)$ & $(.0328)$ & $(.0386)$ & $(.0451)$ & $(.0279)$ & $(.0314)$ \\
\hline Bias-corrected robust & -.00777 & -.0225 & .00444 & .00631 & -.00692 & -.00348 \\
\hline & $(.0427)$ & $(.0370)$ & $(.0433)$ & $(.0494)$ & $(.0323)$ & $(.0329)$ \\
\hline Kernel & Triangular & Uniform & Triangular & Uniform & Triangular & Uniform \\
\hline BW estimation & 6.018 & 6.485 & 12.885 & 8.820 & 8.345 & 8.320 \\
\hline BW bias & 12.519 & 12.720 & 24.841 & 15.612 & 15.368 & 17.654 \\
\hline Observations & 8,680 & 8,680 & 8.680 & 8,680 & 8,680 & 8,680 \\
\hline Effective observations & 2,144 & 2,373 & 2,739 & 2,769 & 2,759 & 2,759 \\
\hline
\end{tabular}

Note. Outcomes are indicators for a given partisan affiliation (Republican in cols. 1-2, Democrat in cols. 3-4, Independent in cols. 5-6). Standard errors are in parentheses. Standard errors for conventional RD estimates are clustered at the state level. Standard errors for bias-corrected RD estimates are Calonico et al.-robust, clustered at the state level. All specifications include year fixed effects. "Effective observations" refers to the number of observations within the estimation BW.

$* p<.1$.

$* * p<.05$.

$* * * p<.01$.

One disadvantage of the NSEE is the relatively small sample sizes. Another source of freely available public opinion data is the Cooperative Congressional Election Survey. The CCES has substantially larger sample sizes than the NSEE. While the CCES has only sporadically asked questions about climate change, it regularly asks detailed questions about partisan identification. I therefore assemble a repeated cross-sectional data set of all publicly available common content survey data from 2006 to 2016 (Ansolabehere and Schaffner 2017). Appendix OB describes these data in more detail. Table OA4 replicates Table 6 using the CCES data. I find no evidence that the election of a Republican governor causes a discontinuous shift in constituents' partisan identification with the large CCES sample. Likewise, using the CCES data, I find no heterogeneous impacts of the party of the governor based on education level. ${ }^{37}$

The 2010-14 CCES panel study surveyed 9,500 individuals in the election years of 2010, 2012, and 2014. Some of these individuals experience a change in the party of their governor throughout the panel. I leverage this within-individual variation to estimate the impact of the election of a Republican governor on an individual's partisan identification. I first drop the 467 individuals who moved to a different state in 2012 or 2014 because these individuals could be simultaneously choosing their partisan identification and the party of their governor. I also drop the 610 individuals who do not report partisan identification in 2010, 2012, or 2014. Of the remaining 8,423 individuals, approximately 9\% change their partisan identification from 2010 to 2012 and 10\% change their partisan identification from 2012 to 2014. To test if the party of the governor affects individual partisan identification, I estimate the simple fixed effects specification,

$$
\mathrm{RP}_{i s t}=\beta_{0}+\beta_{1} \mathrm{RG}_{i s t}+\alpha_{i}+\varphi_{t}+\varepsilon_{i s t}
$$


where $\mathrm{RP}_{\text {ist }}$ is an indicator for an individual $i$ residing in state $s$ in year $t$ who reports a Republican party affiliation, $\mathrm{RG}_{\text {ist }}$ is an indicator for a Republican governor in state $s$ at time $t, \alpha_{i}$ is a time-invariant individual specific fixed effect, and $\phi_{t}$ is a year fixed effect. Identification in this model comes from individuals living in states that experience a change to the partisan identification of the governor. I find no significant effect of a Republican governor on a constituent's partisan identification using this within-individual variation. ${ }^{38}$

Finally, I again use the 2010-14 CCES panel but restrict attention to the 2,573 individuals who report a Republican partisan identity in 2010. Of these 2,573 initially reporting a Republican partisan identity, 154 switch to report either a Democratic or Independent identity in 2012. I then test for differential affiliation switching with the linear probability model,

$$
\text { Switch }_{i s}=\beta_{0}+\beta_{1} \mathrm{RG}_{i s}+\beta_{2} \mathrm{GW}_{i s}+\beta_{3} \mathrm{RG}_{i s} \cdot \mathrm{GW}_{i s}+\varepsilon_{i s},
$$

where Switch $_{\text {is }}$ is an indicator for individual $i$ residing in state $s$ who changed their partisan identity from Republican in 2010 to either Democrat or Independent in 2012, RG is is an indicator for a Republican governor in state $s$ (in 2012), and $\mathrm{GW}_{\text {is }}$ is an indicator for global warming belief (in 2012). A positive and significant $\beta_{3}$ could indicate that Republican voters who believe in climate change are more likely to leave the Republican party when the governor is Republican compared to when the governor is Democrat. However, I find a negative and statistically insignificant differential effect on switching. ${ }^{39}$ In summary, I see no evidence that individuals change their reported partisan identity in response to changes in the party of their governor.

Next, I look for manipulation in the vote margin by examining the density near the threshold. A discontinuous change in the density of the forcing variable at the threshold could be indicative of manipulation. If, for example, the Republican party could precisely forecast a close gubernatorial election outcome and divert enough resources to just move a potential loser over the threshold, there could be a violation of the continuity assumption of the RD design. As the treatment status is defined at the state-year level, I first follow literature in showing the density of state-year level election outcomes. As shown in figure 2, I do not find evidence of manipulation in election outcomes using the state-year-level data. ${ }^{40}$ However, because the main result of the paper concerns differential effects among individuals, I also examine the density of the individual-level observations. Figure 3A shows the McCrary (2008) density plot for the entire sample; the McCrary test statistic is -0.0785 with a standard error of $0.0629 .{ }^{41}$ Recalling the earlier concern that individuals could shift their reported partisan identification based on the gubernatorial winner, I also show density plots when restricting the sample to Democrats (fig. 3B), Republicans (fig. 3C), and Independents (fig. 3D). Again, the density appears continuous through the threshold for these subsamples. ${ }^{42}$ I therefore fail to reject the null of continuous density at the threshold with the individual-level data. 


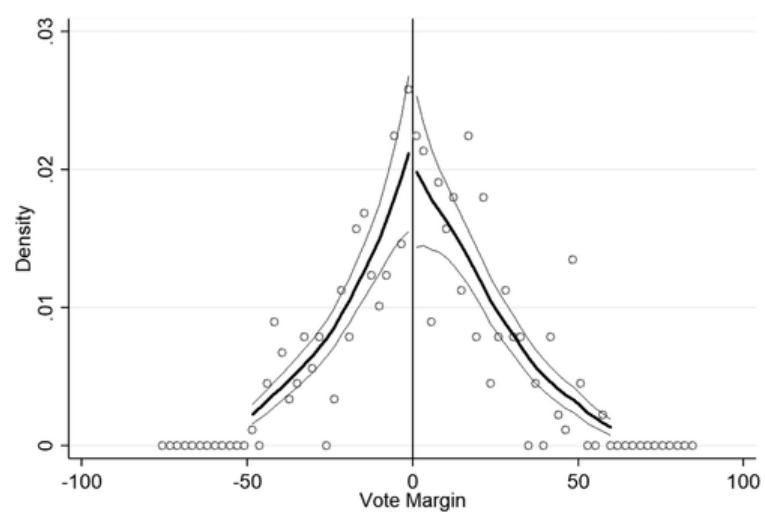

Figure 2. McCrary density plot of vote margin, state-year-level observations. This figure shows the density plot of state-year election outcomes.
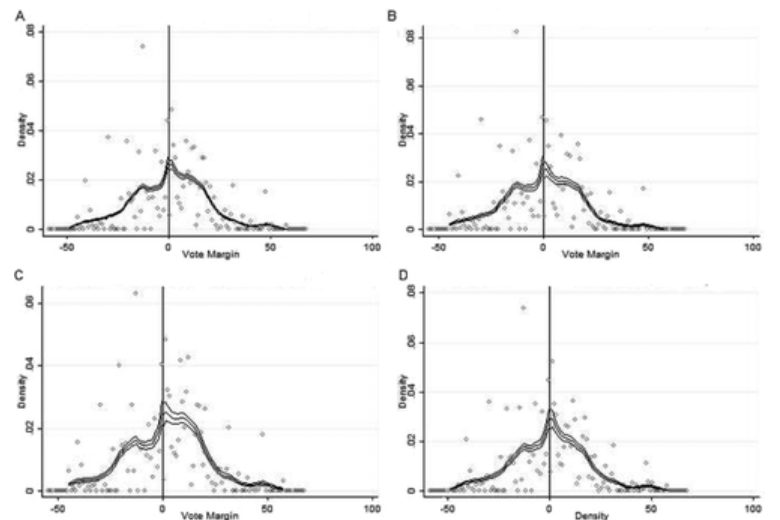

Figure 3. McCrary density plots of vote margin, individual-level observations. Panel $A$ shows the density plot for all respondents. Panel $B$ includes only Democrat respondents. Panel $C$ includes only Republican respondents. Panel $D$ includes only Independent respondents.

Finally, I test for placebo effects of the Republican Governor treatment on the lagged outcome of global warming belief. Specifically, I estimate specifications where I use the global warming beliefs in the years prior to an election. For example, a gubernatorial election took place in Minnesota in 2010. Mark Dayton (Democrat) won the election and took office in January 2011. I pair this election result with the individual-level data on global warming beliefs in Minnesota during the 4 years prior to this election (2007-10). The intuition is that the messaging/policy position for a governor taking office in 2011 should not affect the global warming beliefs of individuals in the prior years. Table A2 shows local linear results for the overall sample, and Table A3 shows results for the specification that tests for differential effects by individual political affiliation, as given by equation (1). I find no evidence that present election outcomes affect past global warming beliefs for the overall sample in Table A2. Furthermore, I find no evidence that present election outcomes differentially affect past global warming beliefs of individuals identifying with different political parties in Table A3. Overall, these validity and falsification tests lend credibility to the claim that I am identifying effects from an exogenous quasi-experiment.

\subsection{Robustness Checks}

Table OA5 shows results for several alternative samples to demonstrate the stability of the estimates. ${ }^{43}$ I first show results with two narrower bandwidths (BW) in column 1 (50\% of optimal BW) 
and column 2 (75\% of optimal BW). The results for these narrower bandwidths are qualitatively unchanged from the baseline results in Table 3. In column 3 of table OA5, I limit the sample to only include observations where the governor has been in power for at least a year. The rationale is that there is a potential delay between when the governor takes office and when the governor's policies and/or messaging are internalized by constituents. Again, the results are quite similar. Table OA6 shows local linear results when I limit the sample to observations where the governor has been in the position for at least a year. Point estimates are larger in absolute value when limiting the sample in this way than for the overall sample. In this case, I also find a statistically significant effect for the overall sample; it appears that this is driven by the strong effect on Republican constituents. Therefore, if anything, the effect of interest gets stronger when I limit the sample to exclude the first year that a governor is in power.

I also widen the bandwidth to use more data further away from the discontinuity. Widening the bandwidth requires adding higher levels of polynomial controls to the RD specification to control for the smooth relationship between vote margin and global warming beliefs. However, there are an infinite combination of bandwidths and parametric controls that one could choose. It is best to avoid choosing bandwidth and order of the polynomial controls in an ad hoc manner. I therefore show results for polynomial controls ranging from order 2 up to order 5, each time using the Calonico et al. optimal-bandwidth calculation. Table OA7 shows that the main qualitative results are unchanged when using higher-order polynomial controls.

The main question of analysis only asks whether an individual believes average temperatures have been rising. As a policy concern, we may also be concerned with belief in anthropogenic climate change. By definition, we have a larger potential influence on anthropogenic climate change as compared to naturally occurring climate change. ${ }^{44}$ I therefore leverage the additional survey question, "Is the earth getting warmer because of human activity such as burning fossil fuels, or mostly because of natural patterns in the earth's environment?" (Rabe and Borick 2017). I define a dichotomous dependent variable as: 1 = human activity or combination of human activity and natural patterns, $0=$ natural patterns or does not believe in any global warming. For reference, approximately $58.7 \%$ of the sample believes in anthropogenic climate change (74.7\% of Democrats, $37.1 \%$ of Republicans, and $59.4 \%$ of Independents). Table 7 presents local linear results; columns 7-9 show that a Republican governor affects the anthropogenic global warming beliefs of a Republican individual much the same as found previously in Table 2 for general global warming beliefs. However, Table 7 also suggests that there is a stronger effect of a Republican governor on Democratic individuals for anthropogenic global warming beliefs as compared to the effect in Table 2 for general global warming beliefs of Democratic individuals. Results for parametric specifications testing for differential effects on anthropomorphic global warming beliefs based on individual political ideology are shown in Table 8; here I do not find significant differential effects. I discuss the divergence in estimated effects on anthropogenic global warming and general global warming beliefs and provide a potential explanation for the difference in section 3 . 
Table 7. Additional Local Linear RD Results: Global Warming Is Due to Humans

\begin{tabular}{|c|c|c|c|c|c|c|c|c|c|}
\hline & $\begin{array}{l}\text { Full } \\
\text { Sample }\end{array}$ & & & $\begin{array}{l}\text { Democrat } \\
\text { Respondents }\end{array}$ & & & $\begin{array}{l}\text { Republican } \\
\text { Respondents }\end{array}$ & & \\
\hline & $(1)$ & $(2)$ & (3) & (4) & (5) & (6) & $(7)$ & $(8)$ & (9) \\
\hline \multirow[t]{2}{*}{ Conventional } & $-.0553 * *$ & $-.0607 * *$ & -.0349 & $-.102 * *$ & $-.113 * *$ & $-.0767^{* *}$ & $-.118 * * *$ & $-.130 * * *$ & $-.0982 * *$ \\
\hline & $(.0273)$ & $(.0282)$ & $(.0309)$ & $(.0473)$ & $(.0459)$ & $(.0385)$ & $(.0379)$ & $(.0359)$ & $(.0423)$ \\
\hline \multirow[t]{2}{*}{ Bias-corrected robust } & $-.0599 *$ & $-.0660 * *$ & -.0229 & $-.113^{* *}$ & $-.124 * * *$ & $-.0873^{*}$ & $-.133 * * *$ & $-.145^{* * *}$ & $-.0972 *$ \\
\hline & $(.0321)$ & $(.0334)$ & $(.0388)$ & $(.0478)$ & $(.0475)$ & $(.0447)$ & $(.0462)$ & $(.0440)$ & $(.0547)$ \\
\hline $\begin{array}{l}\text { Race/ethnicity and } \\
\text { gender }\end{array}$ & & $x$ & $x$ & & $x$ & $x$ & & $x$ & $x$ \\
\hline Kernel & Triangular & Triangular & Uniform & Triangular & Triangular & Uniform & Triangular & Triangular & Uniform \\
\hline BW estimation & 8.163 & 8.043 & 7.647 & 7.560 & 6.923 & 7.409 & 7.701 & 7.520 & 9.399 \\
\hline BW bias & 16.951 & 16.335 & 17.591 & 14.946 & 14.250 & 13.663 & 17.204 & 17.613 & 17.807 \\
\hline Observations & 8,680 & 8,680 & 8,680 & 3,342 & 3,342 & 3,342 & 2,573 & 2,573 & 2,573 \\
\hline Effective observations & 2,759 & 2,759 & 2,657 & 997 & 937 & 997 & 732 & 728 & 923 \\
\hline
\end{tabular}

Note. Standard errors are in parentheses. Standard errors for conventional RD estimates are clustered at the state level. Standard errors for biascorrected RD estimates are Calonico et al.-robust, clustered at the state level. All specifications include year fixed effects. "Effective observations" refers to the number of observations within the estimation BW.

$*_{p}<.1$.

$* * p<.05$.

$* * * p<.01$ 
Table 8. Additional RD Specifications for Differential Effects: Global Warming Is Due to Humans

\begin{tabular}{|l|l|l|l|}
\hline & $(\mathbf{1})$ & $\mathbf{( 2 )}$ & $\mathbf{( 3 )}$ \\
\hline Republican Governor (RG) & -.0679 & -.0643 & $-.0757^{* *}$ \\
\hline & $p=.262$ & $p=.112$ & $p=.042$ \\
\hline RG $\times$ Rep. Individual & -.0476 & -.0335 & -.0109 \\
\hline & $p=.274$ & $p=.400$ & $p=.848$ \\
\hline RG $\times$ Ind. Individual & .0386 & .0670 & .0796 \\
\hline & $p=.576$ & $p=.348$ & $p=.248$ \\
\hline Rep. Individual & $-.331^{* * *}$ & $-.334^{* * *}$ & $-.338^{* * *}$ \\
\hline & $p=.002$ & $p=.002$ & $p=.002$ \\
\hline Ind. Individual & $-.150^{* * *}$ & $-.163^{* * *}$ & $-.161^{* * *}$ \\
\hline & $p=.002$ & $p=.002$ & $p=.002$ \\
\hline Order polynomial controls & 1 & 1 & 1 \\
\hline BW & 8.360 & 8.360 & 7.409 \\
\hline Optimal BW & $\mathrm{X}$ & $\mathrm{X}$ & \\
\hline State fixed effects & $\mathrm{X}$ & & \\
\hline Year fixed effects & $\mathrm{X}$ & & \\
\hline Observations & 2,759 & 2,759 & 2,640 \\
\hline No. of clusters (states) & 29 & 29 & 29 \\
\hline
\end{tabular}

Note. $p$-values are generated using the wild bootstrap procedure from Cameron et al. (2008). Clustering is at the state level. All specifications include controls for race/ethnicity and gender. All specifications include linear controls.

$* p<.1$.

$* * p<.05$

$* * * p<.01$.

The CCES does contain a question about climate change in some years. As discussed in appendix OB, there are several reasons why the CCES data could violate the continuity assumption of the RD design and are not ideal for this application. Nonetheless, the CCES has many more observations and is a wellknown survey, so I briefly discuss RD results only for comparison purposes. Appendix OB describes the CCES climate change question in more detail; I note that the question is not directly comparable to the NSEE climate change question because the CCES bundles action together with belief while the NSEE only inquires about belief. Estimating the preferred specification analogous to column 2 of Table 2, I find a significant treatment effect. The election of a Republican governor is associated with a 6.8 percentage point decrease in the probability of believing that climate change is an issue that requires action. ${ }^{45}$ Therefore, while less reliable than the NSEE analysis, I find a similar overall effect when conducting a parallel analysis on the CCES climate change data.

As a final robustness check, I also use the 2010-14 CCES panel to estimate the fixed effects specification given by equation (2) (replacing Republican partisan identification with an indicator for climate change being an issue that requires action). Again, individuals living in states that experience a change to the partisan identification of their governor provide the identifying variation in this model. I estimate the model first including all individuals and then separately on subsamples of Democrat and 
Republican individuals, as defined by reported 2010 partisan affiliation. As shown in Table A4, I find results that qualitatively agree with the main $\mathrm{RD}$ results. For the overall sample and for the subsample of Democrat respondents, there is no statistical effect of a Republican governor on an individual's belief that climate change is an issue that requires action. But, for Republican respondents, there is a negative effect that is marginally significant ( $p$-value $=.086 p$-value $=.086)$. A Republican governor decreases the probability that a Republican individual believes climate change is an issue that requires action by approximately 3.7 percentage points, providing some external validation of the NSEE RD results.

\section{Discussion}

To summarize the results of section 2, the election of a Republican governor significantly impacts global warming beliefs, relative to the election of a Democratic governor. Focusing on the primary question of whether one believes that global warming is real, the effect is significant for Republican individuals but is not for Democratic individuals. However, on the issue of anthropogenic climate change, the effect is significant for the overall population and does not differ by political identification of the respondent. Here, I provide some possible mechanisms to explain these results.

First, it is possible that there is an overall shift toward conservative values with the election of a Republican governor. If this shift is stronger among Republican individuals than Democratic individuals, it could be an explanation for the differential effects found in section 2 . There is a question about political ideology (ranging from very conservative to very liberal) on some waves of the NSEE. ${ }^{46}$ Estimating a local linear regression analogous to those described in section 2.2 (with "conservative" as the dependent variable), I find no evidence that there is an overall shift toward conservatism with the election of a Republican governor. In the preferred specification analogous to column 2 of Table 2, I find a bias-corrected point estimate of -0.0195 with a standard error of 0.0345 . On the other hand, I find a positive and significant effect in the full CCES sample. There, the election of a Republican governor is associated with an approximate 5 percentage point increase in the probability of a respondent identifying as conservative (significant at the $5 \%$ level). However, as described in appendix $\mathrm{OB}$, results from the CCES sample should be interpreted cautiously because there are some discontinuities in baseline covariates. Nonetheless, it is possible that an overall shift toward conservative values occurs with the election of a Republican governor, relative to the election of a Democrat governor. Future research using other data could help determine to what extent governors affect overall political ideology.

I also estimate equation (1), replacing global warming beliefs with an indicator for conservative. Column 1 of Table A5 shows results for the NSEE sample, and column 2 shows results for the full CCES sample. There is an insignificant effect of a Republican gubernatorial win on the likelihood of a conservative ideology for Democrat individuals. Therefore, shifting ideology is unlikely to explain the significant anthropogenic climate change results for Democratic individuals. Moreover, I do not find any evidence that Republican individuals differentially shift toward more conservative political views relative to Democrat individuals when a Republican governor wins a close election. The coefficient on the differential effect ( $\beta_{3}$ from eq. [1]) is negative and statistically insignificant at conventional levels; if anything, Republican individuals are less prone to shifting toward conservative values with the election of a Republican governor. However, I note that Republican individuals display a substantially higher 
baseline level of conservatism as they are approximately 70 percentage points more likely to report conservative political views relative to a Democrat individual.

Evidence is growing that the media affects individuals' pro-environmental beliefs and behavior. For example, Jacobsen (2011) finds that the climate change documentary, An Inconvenient Truth, substantially increased carbon offset purchases, and Beattie (2017a) finds that consumers become more skeptical about climate change when the tone of newspaper coverage becomes more skeptical about the issue. Relatedly, Beattie (2017b) finds that recent newspaper coverage with an environmental tone causes households to be more environmentally friendly in their driving behavior. Thus, differential engagement with local news based on partisan identification could partially explain differential impacts of a Republican governor on climate change beliefs. CCES asks a question about how informed respondents are about the news. Table A6 shows the results of a descriptive ordinary least squares (OLS) regression of news engagement on observable characteristics. Interestingly, relative to the omitted partisan category of Democrat, Republican individuals are 2.4 percentage points more likely to report being well informed on the news, and Independent individuals are 1.8 percentage points less likely to report being well informed on the news. While not a causal explanation, these correlations suggest that engagement with the news could partially explain why Republican individuals are more susceptible to changing their climate change beliefs.

Finally, that results differ among Democrat individuals for general global warming beliefs versus anthropogenic global warming beliefs is somewhat puzzling. Why would communication from a governor matter more for anthropogenic global warming beliefs than for general global warming beliefs for Democrat respondents? Within the optimal bandwidth for Democrat individuals from the main specification in column 4 of Table $2,85.4 \%$ of Democrat respondents believe average temperatures have been rising over the past 4 decades and $76.0 \%$ believe warming is occurring and at least partially human caused. And, within the optimal bandwidth for Republican individuals from the main specification in column 6 of Table 2, 50.4\% of Republican respondents believe average temperatures have been rising over the past 4 decades and $35.1 \%$ believe warming is occurring and at least partially human caused. Table A7 summarizes observable characteristics for these four groups of respondents, along with observable characteristics for individuals of both parties who do not believe in any global warming. The numbers in each cell represent the proportion of respondents falling into a given belief category that displays a certain characteristic. ${ }^{47}$ For Republicans, average observable characteristics look quite similar across the three belief categories. However, for Democrats, observable characteristics correlate with the global warming belief category. Democrats who believe in only natural global warming are more likely to be nonwhite, female, and non-college-educated relative to those who believe in human-caused global warming. The difference in the proportion of collegeeducated individuals is particularly striking. Also, there is a Republican governor in office $68 \%$ of the time when a Democrat individual believes only in naturally caused global warming. These descriptive differences suggest that the election of a Republican governor is not likely to cause a Democratic global warming believer to completely deny global warming, but it could sway a marginal, especially lowereducated, Democrat to deny human causes of global warming. Interestingly, education does not seem to play a similar role in the case of Republican individuals, which is consistent with prior findings in the literature. 


\section{Conclusion}

In summary, this paper provides evidence that political leaders' messaging and policies can affect global warming beliefs of constituents, and the effect is strongest among Republican individuals. I use survey data from the United States to establish the causal effect of the political party of a governor on the climate change beliefs of constituents. In a local linear RD specification on the subset of Republican individuals, the election of a Republican governor decreases the absolute probability of a Republican constituent believing in global warming by approximately 14 percentage points. ${ }^{48}$ Additional specifications on the pooled data find evidence that a Republican governor differentially affects the probability of global warming beliefs for individuals affiliated with different political parties; Republican individuals become approximately 11 percentage points less likely to state that global warming is real compared to Democratic individuals. These findings are robust to alternative specifications and sample selection criteria.

Research suggests that individuals look to their political leaders to develop opinions on complex issues such as climate change. Additionally, previous literature provides reason to expect that the political party of the governor could differentially affect the global warming beliefs of Democratic and Republican constituents. Political affiliation has been shown to be one of the most important predictors of climate change beliefs, and political affiliation moderates the impact of scientific information on climate change beliefs. It is also established that experimentally manipulating the frame of how global warming information is conveyed to constituents typically has larger impacts on Republican individuals than on Democratic individuals.

While this previous research helps justify why we may expect to find differential impacts on Democratic and Republican individuals, the specific channel by which the political party of the governor affects global warming beliefs remains largely an open question. One possibility is that individuals listen to informational communication from the elected official when forming their climate change beliefs. Another possibility, consistent with Broockman and Butler (2017), is that the simple position adoption of the elected official is what sways opinion; the content of the message does not matter. Future research focused on the specific mechanism(s) by which governors sway public opinion on climate change would be valuable, especially considering the rather large estimated effect size for Republican individuals. More generally, it would also be useful to further explore what other types of public opinion governors may affect. Regardless of the transmission mechanism, the policy implication is clear. It will likely remain difficult to convert climate change skeptics so long as their political leaders publicly exhibit skeptical positions.

Previous research documents a growing polarization in climate change beliefs between Democrats and Republicans. This paper provides one explanation why this could happen even as the scientific consensus on the existence and impacts of climate change becomes stronger. Furthermore, in addition to the scientific consensus, there is growing consensus around the economic argument for reducing carbon emissions. ${ }^{49}$ As long as the political elite maintain skepticism of these economic arguments, public opinion will likely continue to polarize, and meaningful climate policy may remain elusive.

\section{Appendix. Additional Results Tables}

Table A1. Tests for Differences in Proportion of Observable Characteristics by Treatment Status 


\begin{tabular}{|l|l|l|l|l|}
\hline Characteristic & $\begin{array}{l}\text { Proportion, Left of the } \\
\text { RD Threshold }\end{array}$ & $\begin{array}{l}\text { Proportion, Right of the } \\
\text { RD Threshold }\end{array}$ & $\begin{array}{l}\text { Difference in } \\
\text { Proportion (p-value) }\end{array}$ & $\boldsymbol{n}$ \\
\hline Male & .488 & .477 & .0109 & 2,144 \\
\hline & & & $(p=.618)$ & \\
\hline $\begin{array}{l}\text { College } \\
\text { educated }\end{array}$ & .474 & .479 & -.00468 & 2,140 \\
\hline & & & $(p=.830)$ & \\
\hline White & .858 & .843 & .0153 & 2,144 \\
\hline & & & $(p=.326)$ & \\
\hline Age 45 or older & .732 & .729 & .00325 & 2,123 \\
\hline & & & $(p=.868)$ & \\
\hline Conservative & .417 & .408 & .00970 & 1,930 \\
\hline & & & $(p=.668)$ & \\
\hline Republican & .273 & .296 & -.0226 & 2,144 \\
\hline & & & $(p=.251)$ & \\
\hline Democrat & .379 & .363 & .0164 & 2,144 \\
\hline & & & $(p=.437)$ & \\
\hline Independent & .348 & .342 & .00626 & 2,144 \\
\hline & & & $(p=.763)$ & \\
\hline
\end{tabular}

Note. This table reports tests for differences in proportion of male, college educated, white, older, conservative, Republican, Democrat, and Independent respondents for individuals just below the threshold ( $6 \leq$ vote margin $<0)$ versus individuals just above the threshold $(0<$ vote margin $\leq 6)$.

Table A2. Falsification Test for Lagged Global Warming Beliefs: Local Linear RD

\begin{tabular}{|l|l|l|}
\hline & $(\mathbf{1})$ & $\mathbf{( 2 )}$ \\
\hline Conventional & -.0180 & .0150 \\
\hline & $(.0196)$ & $(.0276)$ \\
\hline Bias-corrected robust & -.0254 & .00701 \\
\hline & $(.0222)$ & $(.0297)$ \\
\hline Kernel & Triangular & Uniform \\
\hline Optimal BW & $\mathrm{X}$ & $\mathrm{X}$ \\
\hline BW estimation & 7.351 & 6.844 \\
\hline BW bias & 15.674 & 15.911 \\
\hline Observations & 7,679 & 7,697 \\
\hline Effective observations & 2,819 & 2,819 \\
\hline
\end{tabular}

Note. Standard errors are in parentheses. Standard errors for conventional RD estimates are clustered at the state level. Standard errors for bias-corrected RD estimates are Calonico et al.-robust, clustered at the state level. All specifications include year fixed effects. "Effective observations" refers to the number of observations within the estimation BW.

$* p<.1$.

$* * p<.05$.

$* * * p<.01$.

Table A3. Falsification Test for Lagged Global Warming Beliefs: RD Specifications for Differential Effects 


\begin{tabular}{|l|l|l|}
\hline & (1) & (2) \\
\hline Republican Governor (RG) & .0620 & .0391 \\
\hline & $p=.454$ & $p=.748$ \\
\hline RG $\times$ Republican Individual & -.0690 & -.0542 \\
\hline & $p=.498$ & $p=.584$ \\
\hline RG $\times$ Independent Individual & -.0824 & -.0518 \\
\hline & $p=.11$ & $p=.356$ \\
\hline BW & 7.479 & 10.051 \\
\hline Optimal BW & $\mathrm{X}$ & \\
\hline Observations & 2,819 & 3,748 \\
\hline No. of clusters (states) & 25 & 29 \\
\hline
\end{tabular}

Note. $p$-values are generated using the wild bootstrap procedure from Cameron et al. (2008). Clustering is at the state level. All specifications include controls for race/ethnicity and gender, individual partisan affiliation, state fixed effects, and year fixed effects. All specifications include linear controls.

$* p<.1$.

$* * p<.05$.

$* * * p<.01$.

Table A4. Panel Fixed-Effects Results for Global Warming Action, CCES Data

\begin{tabular}{|l|l|l|l|}
\hline & $\begin{array}{l}\text { Full Sample } \\
(\mathbf{1})\end{array}$ & $\begin{array}{l}\text { Democrat Respondents } \\
\text { (2) }\end{array}$ & $\begin{array}{l}\text { Republican Respondents } \\
\text { (3) }\end{array}$ \\
\hline Republican Governor (RG) & -.00802 & .0115 & $-.0366^{*}$ \\
\hline & $p=.644$ & $p=.532$ & $p=.0860$ \\
\hline Observations & 24,940 & 9,531 & 7,601 \\
\hline Individuals & 8,407 & 3,195 & 2,573 \\
\hline No. of clusters (states) & 50 & 50 & 50 \\
\hline
\end{tabular}

Note. $p$-values are generated using the wild bootstrap procedure from Cameron et al. (2008). Clustering is at the state level. See app. OB for a description of the CCES global warming data.

$* p<.1$.

$* * p<.05$.

$* * * p<.01$.

Table A5. Effects on Conservative Ideology: RD Specifications for Differential Effects

\begin{tabular}{|l|l|l|}
\hline & $\begin{array}{l}\text { NSEE } \\
\text { (1) }\end{array}$ & $\begin{array}{l}\text { CCES } \\
\text { (2) }\end{array}$ \\
\hline Republican Governor (RG) & .0183 & .0242 \\
\hline & $p=.906$ & $p=.314$ \\
\hline RG $\times$ Rep. Individual & -.0896 & -.0625 \\
\hline & $p=.190$ & $p=.118$ \\
\hline RG $\times$ Ind. Individual & -.103 & -.0348 \\
\hline & $p=.126$ & $p=.336$ \\
\hline Rep. Individual & $.698^{* * *}$ & $.685^{* * *}$ \\
\hline
\end{tabular}




\begin{tabular}{|l|l|l|}
\hline & $\begin{array}{l}\text { NSEE } \\
(\mathbf{1})\end{array}$ & $\begin{array}{l}\text { CCES } \\
\text { (2) }\end{array}$ \\
\hline & $p<.001$ & $p<.001$ \\
\hline Ind. Individual & $.217^{* * *}$ & $.178^{* * *}$ \\
\hline & $p<.001$ & $p<.001$ \\
\hline Order polynomial controls & 1 & 1 \\
\hline BW & 10.698 & 7.108 \\
\hline Optimal BW & $\mathrm{X}$ & $\mathrm{X}$ \\
\hline Observations & 2,949 & 98,526 \\
\hline No. of clusters (states) & 32 & 38 \\
\hline
\end{tabular}

Note. The dependent variable in this table is an indicator for self-reported conservative ideology. $p$-values are generated using the wild bootstrap procedure from Cameron et al. (2008). Clustering is at the state level. All specifications include controls for race/ethnicity and gender, state fixed effects, and year fixed effects.

$* p<.1$.

$* * p<.05$.

$* * * p<.01$.

Table A6. News Engagement: Descriptive OLS Results, CCES Data

\begin{tabular}{|l|l|}
\hline & $\begin{array}{l}\text { Informed on News } \\
(\mathbf{1})\end{array}$ \\
\hline Rep. Individual & $.0243^{* * *}$ \\
\hline & $(.00378)$ \\
\hline Ind. Individual & $-.0178^{* * *}$ \\
\hline & $(.00356)$ \\
\hline Male & $.0840^{* * *}$ \\
\hline & $(.00233)$ \\
\hline College educated & $.120^{* * *}$ \\
\hline & $(.00274)$ \\
\hline Age 45 and older & $.149^{* * *}$ \\
\hline & $(.00312)$ \\
\hline African American & $-.0724 * * *$ \\
\hline & $(.00569)$ \\
\hline Asian & $-.102^{* * *}$ \\
\hline & $(.00701)$ \\
\hline Hispanic/Latino & $-.126^{* * *}$ \\
\hline & $(.0132)$ \\
\hline Mixed race and other & .00736 \\
\hline & $(.00681)$ \\
\hline State fixed effects & $\mathrm{X}$ \\
\hline & \\
\hline
\end{tabular}




\begin{tabular}{|l|l|}
\hline & $\begin{array}{l}\text { Informed on News } \\
\text { (1) }\end{array}$ \\
\hline Year fixed effects & X \\
\hline Observations & 291,794 \\
\hline No. of clusters (states) & 50 \\
\hline
\end{tabular}

Note. The dependent variable in this table is an indicator for self-reported conservative ideology. Standard errors in parentheses are clustered at the state level. CCES = Cooperative Congressional Election Survey.

$* p<.1$.

$* * p<.05$.

$* * * p<.01$.

Table A7. Description of Observable Characteristics by Partisan Affiliation and Global Warming Belief Category

\begin{tabular}{|c|c|c|c|c|c|c|}
\hline & $\begin{array}{l}\text { Democrat } \\
\text { Individual }\end{array}$ & & & $\begin{array}{l}\text { Republican } \\
\text { Individual }\end{array}$ & & \\
\hline Variable & $\begin{array}{l}\text { Human } \\
\text { Caused Global } \\
\text { Warming }\end{array}$ & $\begin{array}{l}\text { Only Natural } \\
\text { Global } \\
\text { Warming }\end{array}$ & $\begin{array}{l}\text { No Global } \\
\text { Warming }\end{array}$ & $\begin{array}{l}\text { Human Caused } \\
\text { Global } \\
\text { Warming }\end{array}$ & $\begin{array}{l}\text { Only Natural } \\
\text { Global } \\
\text { Warming }\end{array}$ & $\begin{array}{l}\text { No Global } \\
\text { Warming }\end{array}$ \\
\hline White/Caucasian & .819 & .631 & .737 & .940 & .954 & .933 \\
\hline Male & .458 & .320 & .444 & .457 & .496 & .517 \\
\hline $\begin{array}{l}\text { College } \\
\text { educated }\end{array}$ & .551 & .243 & .271 & .507 & .450 & .447 \\
\hline Age 45 or older & .715 & .757 & .760 & .691 & .744 & .787 \\
\hline Rep. governor & .546 & .680 & .550 & .619 & .641 & .647 \\
\hline
\end{tabular}

Note. This table shows the proportion of respondents falling into a given belief category that display a certain observable characteristic.

\section{Notes}

Andrew G. Meyer is at Marquette University, Department of Economics, 1225 W. Wisconsin Avenue, Milwaukee, WI 53233 (andrew.g.meyer@marquette.edu). I thank two anonymous reviewers for comments that greatly improved the quality of the paper. I also thank conference participants at the 2018 AERE sessions of the MEA meetings in Evanston, IL, and seminar participants at the University of Wisconsin-Milwaukee for helpful comments.

1. I use the terms "climate change" and "global warming" interchangeably throughout the paper. Global warming was the more popular term in the 1970s and 1980s but continues to appear in the lexicon. "Climate change" often implies a wider range of impacts, such as increased climate variability and sea level rise. The question on the survey that I analyze uses the term "global warming." 
2. Political polarization is not limited to climate change. A literature documents growing political polarization on a variety of economic and social issues (Evans 2003; Brewer 2005; Abramowitz and Saunders 2008; Baldassarri and Gelman 2008).

3. A growing literature seeks to quantify the economic effects of climate change. Dell et al. (2014) provide a review of studies using weather shocks over time to identify economic impacts. Examples of papers using this approach are Deschênes and Greenstone (2007, 2011), Schlenker and Roberts (2009), Barreca (2012), Dell et al. (2012), Fisher et al. (2012), Barreca et al. (2016), and Graff Zivin et al. (2018). Cragg and Kahn (1997) and Sinha et al. (2018) use discrete choice models of locational choice to estimate willingness to pay for climate amenities. Similarly, Albouy et al. (2016) use a hedonic framework to estimate household welfare losses due to changing temperatures. A recent review on the economic costs of climate change is provided by Tol (2018).

4. Similar to Costa and Kahn (2013b), I take political ideology as a set of prior beliefs. Given their political affiliation/ideology, individuals are "treated" with a gubernatorial election result. I provide evidence in sec. 2.4 to support this stance.

5. For a recent example with an application to climate change beliefs, see Shapiro (2016).

6. Kahn and Zhao (2017) examine how climate skepticism affects market outcomes including, innovation, migration, and real estate prices.

7. One could recast the causal effect into an equivalent statement that a Democratic gubernatorial win significantly increases the probability of a Republican constituent believing in global warming. It is not possible to separate these two interpretations of the results. For clarity in exposition, I maintain the interpretation of the causal effect of a close Republican gubernatorial win throughout the paper.

8. Kousser and Tranter (2018) provide recent experimental evidence that Australian political leaders can influence survey respondents. I am not aware of any prior quasi-experimental research that identifies the impact of political elite on climate change beliefs.

9. Several notable exceptions that use quasi-experiments to identify the effect of elite positions on public beliefs include Broockman (2009), Lenz (2009), and Carlsson et al. (2016). Some experimental papers do control elite communication in a laboratory or field experiment setting to establish causality (e.g.. Druckman 2004; Gerber et al. 2009, 2011; Druckman et al. 2013; Broockman and Butler 2017). While such experimental studies have high internal validity, the external validity of the results remains an open question.

10. For example, Costa and Kahn (2013b) show that political ideology matters for the response to a electricity conservation "nudge," Costa and Kahn (2013a) find that liberal households consume less electricity, and Kahn (2007) finds that members of the Green Party make more environmentally friendly transportation choices.

11. Cragg et al. (2013) highlight that the average League of Conservation Voters score (a popular measure of how pro-environment a member of Congress is in their voting positions) for the leadership of the Democrats in 2009 was $93 \%$ and that of the Republican leadership was $0 \%$. Multiple academic articles have detailed the history of climate change denial within the conservative movement (e.g., McCright and Dunlap 2003; Jacques et al. 2008; Elsasser and Dunlap 2013; Egan and Mullin 2017). 
12. Perhaps the most well-known exceptions, Arnold Schwarzenegger (Republican governor of California from November 17, 2003, to January 3, 2011) and Charlie Crist (Republican governor of Florida from January 2, 2007, to January 4, 2011) advocated for policies to address climate change. Observations from Florida in 2010 are not included in any of the analyses because Crist switched to Independent in early 2010. Crist later switched to the Democatic Party in 2012. Results are not sensitive to the exclusion of California under Schwarzenegger or Florida under Crist.

13. There is an entire literature devoted to theories and evidence concerning the impact of elite behavior on mass opinion. Some examples include Carmines and Stimson (1989), Brody (1991), Zaller (1992), Hetherington (2001), Kam (2005), and Levendusky (2010).

14. Governors serve 2-year terms in these two states.

15. Governors are the elected executive heads of each US state. As detailed by Beland (2015), governors wield considerable political power in the US political system as the head of the executive branch. "The governor sets policies, prepares and administers a budget, recommends legislation, signs laws, and appoints department heads. ... Governors can veto state bills, which gives them considerable control over policies" (Beland 2015, 199).

16. For New Hampshire and Vermont, $t+1$ to $t+2$ because of the 2 -year terms.

17. Respondents were interviewed in English on landlines and cell phones (only landlines in 2008). Phone numbers were chosen randomly from US numbers provided by a marketing company. Both landlines and cell phones were called up to 10 times to reach a representative sample of adult Americans (Rabe and Borick 2017). Other commonly utilized survey data sources are the American National Election Studies (ANES) and the Cooperative Congressional Election Survey (CCES). The ANES Time Series Study only asks global warming questions in 2012 and 2016 and is hence not an appropriate data source for this research question. I present results using CCES data as a robustness check in sec. 2.5 but discuss reasons why these data may be unreliable for $\mathrm{RD}$ analysis in app. OB.

18. Of the respondents, 9,137 individuals provide global warming beliefs and have a Democratic or Republican governor, 377 individuals report "other party" and are excluded, and 4 individuals report "not sure" and are excluded. Thus, all respondents in the sample report Democrat, Republican, or Independent for their political party affiliation. There are no other questions concerning party affiliation in the NSEE.

19. Results are not sensitive to the inclusion of individuals who do not report race/ethnicity.

20. Note that Hispanics may be of any race in the census data, so they are also included in the race percentages. In contrast, race/ethnicity categories in the NSEE are mutually exclusive.

21. I use a bin size of 1 and an integer bandwidth of 10, which is approximately equal to the optimal bandwidth of the local linear regressions of the next subsection.

22. The states represented in the bins nearest the threshold are as follows: $-6 \leq$ vote margin $\leq-3$ : Colorado, Delaware, Louisiana, Minnesota, Montana, North Carolina, Oregon, Rhode Island, Virginia, West Virginia, Washington. $-3 \leq$ vote margin < -0: Connecticut, Illinois, Minnesota, Montana, North Carolina, Oregon, Virginia, Vermont, Washington. $0 \leq$ vote margin < 3: Florida, Indiana, Maine, Massachusetts, Minnesota, Missouri, New Hampshire, Ohio, Rhode Island. $3 \leq$ vote margin < 6: Illinois, Indiana, Kansas, Maine, Maryland, Michigan, Missouri, Nevada, New Jersey, South Carolina. 
23. I present evidence in sec. 2.4 to support the continuity assumption.

24. I also show results using a uniform kernel in table OA1.

25. When viewing RD as a nonparametric estimation problem, local linear regressions allow for an arbitrary relationship between the running variable (vote margin) and the outcome (belief in global warming) near the RD threshold. In contrast, point estimates and inference in the parametric view of RD assume that the functional form of the regression relationship is a known polynomial (possibly also linear). As noted by Lee and Lemieux (2010, 284), "the main difference, then, between a parametric and nonparametric approach is not in the actual estimation but rather in the discussion of the asymptotic behavior of the estimator as sample sizes tend to infinity." In practice, this means that bias correction of the RD treatment effect should be used when viewing RD as a nonparametric problem. In contrast, conventional parametric RD approaches would ignore the bias.

26. Calonico et al. (2018) expand the methods of Calonico et al. (2014b) to allow for covariates and clustered data. I use the rdrobust package (Calonico et al. 2017) within Stata for all local linear regressions, incorporating the default MSE-optimal bandwidth for clustered standard errors. I use the "cluster" option for all local linear regressions, as described in Calonico et al. (2017, 2018). See Bartalotti and Brummet (2017) for more detail on RD bandwidth selection and estimation with clustered data.

27. For example, the conventional RD estimator with linear controls is given by the specification, GWist $=\alpha+\beta \cdot R G s t+\phi \cdot V M s t+\lambda \cdot R G s t \cdot V M s t+\gamma$ Xist $+\varepsilon i s t G W i s t=\alpha+\beta \cdot R G s t+\phi \cdot V M s t+\lambda \cdot R G s$

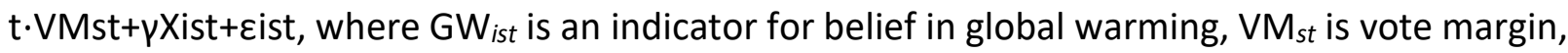
$\mathrm{RG}_{s t}$ is an indicator for a Republican governor holding office, and $X_{\text {ist }}$ includes baseline covariates for individual $i$ residing in state $s$ in year $t$.

28. These results use the triangular kernel. Results using the uniform kernel are similar and shown in table OA1. Results excluding year fixed effects are similar to those reported in Table 2 and are available upon request. When limiting the sample to Independent respondents only, I find positive coefficients that are statistically insignificant. The bias-corrected point estimates for Independent respondents are 0.0459 (with a standard error of 0.0386 ) when using only year effects as baseline controls and 0.0561 (with a standard error of 0.0355 ) when conditioning on year effects, race/ethnicity, and gender. Because of these positive point estimates, I check extensively for the possibility of endogenous partisan affiliation in sec. 2.4.

29. I use the rdrobust package to find the optimal bandwidth for the overall sample, conditioning on survey year fixed effects, race/ethnicity, gender, and partisan affiliation. I use the uniform kernel and cluster standard errors at the state level for the optimal bandwidth calculation. All $p$ values in this section are calculated using the wild cluster bootstrap with 1,000 replications. The wild cluster bootstrap is recommended for cluster-robust inference with a small number of clusters (Cameron et al. 2008; Cameron and Miller 2015). I use the cgmwildboot command from Judson Caskey's website (https://sites.google.com/site/judsoncaskey/data) to obtain $p$ values based on the bootstrap distribution of $t$-statistics.

30. Skovron and Titiunik (2015) recommend recalculating the optimal bandwidth for each placebo outcome.

31. I also conduct a placebo test where I first regress global warming beliefs on all baseline controls, generate fitted values for predicted beliefs, and then test for discontinuous predicted 
beliefs (using the Calonico et al. optimal bandwidth). I find no evidence of discontinuous predicted beliefs. These results appear in table OA2.

32. For each outcome in Table 5, I use the Calonico et al. optimal bandwidth. I use linear controls and the uniform kernel. I use race/ethnicity, gender, and year fixed effects as covariates for the bandwidth calculation.

33. See Table 3, for example.

34. In each case, individuals identifying with the corresponding outcome party of interest are coded as 1 and all others are coded as 0. I use the Calonico et al. optimal bandwidth in all specifications.

35. Columns 1-3 use the optimal bandwidths from the analogous specifications for the outcome of global warming belief.

36. While not statistically significant, signs on the point estimates in cols. 4-5 of table OA3 run counter to the argument that less educated individuals are pushed to the Republican party and more educated individuals are pushed away from the Republican party with the election of a Republican governor.

37. Point estimates are small in magnitude and never statistically significant. These results are available by request.

38. The coefficient $\beta_{1}$ is estimated at -0.00725 with a $p$-value of 0.27 (using the wild cluster bootstrap with 1,000 replications).

39. I condition on race/ethnicity, gender, and education. The coefficient $\beta_{3}$ is estimated at -0.0844 with a standard error of 0.0872 (clustered at the state level).

40. The McCrary test statistic is -0.0827 with a standard error of 0.120 .

41. Consistent with fig. 1, I use a bandwidth of 10 and a bin size of 1 for the McCrary density plots shown in fig. 3. I use the user-written DCdensity command in Stata (McCrary 2008).

42. The relevant McCrary test statistics (with standard errors in parentheses) are: -0.125 (0.102) for Democrats, -0.0827 (0.120) for Republicans, and -0.0243 (0.107) for Independents.

43. Each of these specifications uses linear controls. Additional results using higher-order polynomial controls are similar and available upon request.

44. A policy to decrease naturally occurring global warming would require geoengineering solutions. Moreover, it is not clear that the public would support costly policies to address natural warming.

45. The bias-corrected point estimate is -0.0678 with a standard error of 0.0213 (clustered at the state level). As discussed in app. OB, there is a discontinuous change in partisan affiliation in the CCES climate change data at the RD threshold. Therefore, it is not advisable to examine heterogeneity by partisan affiliation in these data.

46. Political ideology appears on the NSEE beginning in the fall 2010 survey wave. I create an indicator for "conservative," which equals 1 if the respondent identifies as "very conservative" or "somewhat conservative" and 0 if the respondent identifies as "moderate," "somewhat liberal," or "very liberal."

47. For example, among Democrats who believe in human caused global warming, $81.9 \%$ are white.

48. Again, an equivalent statement is "the election of a Democratic governor increases the absolute probability of a Republican constituent believing in global warming by approximately 14 percentage points." 
49. Economists typically favor placing a price on carbon via a tax or tradable permit system. For an example of survey evidence of climate change economics experts, see Howard and Sylvan (2015).

\section{References}

Abramowitz, Alan I., and Kyle L. Saunders. 2008. Is polarization a myth? Journal of Politics 70 (2): 542-55. doi:10.1017/S0022381608080493.

Albouy, David, Walter Graf, Ryan Kellogg, and Hendrik Wolff. 2016. Climate amenities, climate change, and American quality of life. Journal of the Association of Environmental and Resource Economists 3 (1): 20546. doi:10.1086/684573.

Ansolabehere, Stephen, and Brian F. Schaffner. 2017. CCES common content, 2016. doi:10.7910/DVN/GDF6Z0, Harvard Dataverse, V4.

Atkeson, Lonna Rae, and Randall W. Partin. 2001. Candidate advertisements, media coverage, and citizen attitudes: The agendas and roles of senators and governors in a federal system. Political Research Quarterly 54 (4): 795-813. doi:10.1177/106591290105400406.

Baldassarri, Delia, and Andrew Gelman. 2008. Partisans without constraint: Political polarization and trends in American public opinion. American Journal of Sociology 114 (2): 408-46. doi:10.1086/590649.

Barreca, Alan I. 2012. Climate change, humidity, and mortality in the United States. Journal of Environmental Economics and Management 63 (1): 19-34. doi:10.1016/j.jeem.2011.07.004.

Barreca, Alan, Karen Clay, Olivier Deschênes, Michael Greenstone, and Joseph S. Shapiro. 2016. Adapting to climate change: The remarkable decline in the US temperature-mortality relationship over the twentieth century. Journal of Political Economy 124 (1): 105-59. doi:10.1086/684582.

Bartalotti, Otávio, and Quentin Brummet. 2017. Regression discontinuity designs with clustered data. In Regression discontinuity designs. Vol. 38, 383-420. Emerald. doi:10.1108/S0731905320170000038017.

Beattie, Graham. 2017a. Advertising, media capture, and public opinion: The case of climate change. Unpublished manuscript, Loyola Marymount University.

- - . 2017b. The social cost of "fake news": How media coverage of climate change affects behavior. Unpublished manuscript.

Beland, Louis-Philippe. 2015. Political parties and labor-market outcomes: Evidence from US states. American Economic Journal: Applied Economics 7 (4): 198-220.

Beland, Louis-Philippe, and Vincent Boucher. 2015. Polluting politics. Economics Letters 137:176-81. doi:10.1016/j.econlet.2015.11.007.

Beland, Louis-Philippe,, and Sara Oloomi. 2017. Party affiliation and public spending: Evidence from U.S. governors. Economic Inquiry 55 (2): 982-95. doi:10.1111/ecin.12393.

Beland, Louis-Philippe, and Bulent Unel. 2018. The impact of party affiliation of US governors on immigrants' labor market outcomes. Journal of Population Economics 31 (2): 627-70. doi:10.1007/s00148-0170663-y.

Borick, Christopher P., and Barry G. Rabe. 2010. A reason to believe: Examining the factors that determine individual views on global warming. Social Science Quarterly 91 (3): 777-800. doi:10.1111/j.15406237.2010.00719.x.

Brewer, Mark D. 2005. The rise of partisanship and the expansion of partisan conflict within the American electorate. Political Research Quarterly 58 (2): 219-29. doi:10.1177/106591290505800203.

Brody, Richard A. 1991. Assessing the president: The media, elite opinion, and public support. Stanford, CA: Stanford University Press.

Broockman, David E. 2009. Do congressional candidates have reverse coattails? Evidence from a regression discontinuity design. Political Analysis 17 (4): 418-34. doi:10.1093/pan/mpp013. 
Broockman, David E,. and Daniel M. Butler. 2017. The causal effects of elite position-taking on voter attitudes: Field experiments with elite communication. American Journal of Political Science 61 (1): 208-21. doi:10.1111/ajps.12243.

Calonico, Sebastian, Matias D. Cattaneo, Max H. Farrell, and Rocio Titiunik. 2017. Rdrobust: Software for regression-discontinuity designs. Stata Journal 17 (2): 372-404.

- - . 2018. Regression discontinuity designs using covariates. Review of Economics and Statistics, forthcoming.

Calonico, Sebastian, Matias D. Cattaneo, and Rocio Titiunik. 2014a. Robust data-driven inference in the regression-discontinuity design. Stata Journal 14 (4): 909-46.

- - 2014b. Robust nonparametric confidence intervals for regression-discontinuity designs. Econometrica 82 (6): 2295-2326. doi:10.3982/ECTA11757.

Cameron, A. Colin, Jonah B. Gelbach, and Douglas L. Miller. 2008. Bootstrap-based improvements for inference with clustered errors. Review of Economics and Statistics 90 (3): 414-27.

Cameron, A. Colin, and Douglas L. Miller. 2015. A practitioner's guide to cluster-robust inference. Journal of Human Resources 50 (2): 317-72.

Carlsson, Magnus, Gordon B. Dahl, and Dan-Olof Rooth. 2016. Do politicians change public attitudes? Unpublished manuscript, Centre for Labour Market and Discrimination Studies, Linnaeus University.

Carmines, Edward G., and James A. Stimson. 1989. Issue evolution: Race and the transformation of American politics. Princeton, NJ: Princeton University Press.

Caughey, Devin, and Jasjeet S. Sekhon. 2011. Elections and the regression discontinuity design: Lessons from close U.S. House races, 1942-2008. Political Analysis 19 (4): 385-408.

Costa, Dora L., and Matthew E. Kahn. 2013a. Do liberal home owners consume less electricity? A test of the voluntary restraint hypothesis. Economics Letters 119 (2): 210-12. doi:10.1016/j.econlet.2013.02.020.

- - . 2013b. Energy conservation "nudges" and environmentalist ideology: Evidence from a randomized residential electricity field experiment. Journal of the European Economic Association 11 (3): 680-702. doi:10.1111/jeea.12011.

Cragg, Michael, and Matthew Kahn. 1997. New estimates of climate demand: Evidence from location choice. Journal of Urban Economics 42 (2): 261-84. doi:10.1006/juec.1996.2027.

Cragg, Michael I., Yuyu Zhou, Kevin Gurney, and Matthew E. Kahn. 2013. Carbon geography: The political economy of congressional support for legislation intended to mitigate greenhouse gas production. Economic Inquiry 51 (2): 1640-50. doi:10.1111/j.1465-7295.2012.00462.x.

de la Cuesta, Brandon, and Kosuke Imai. 2016. Misunderstandings about the regression discontinuity design in the study of close elections. Annual Review of Political Science 19 (1): 375-96. doi:10.1146/annurevpolisci-032015-010115.

Dell, Melissa, Benjamin F. Jones, and Benjamin A. Olken. 2012. Temperature shocks and economic growth: Evidence from the last half century. American Economic Journal: Macroeconomics 4 (3): 66-95.

- - . 2014. What do we learn from the weather? The new climate economy literature. Journal of Economic Literature 52 (3): 740-98.

DellaVigna, Stefano, and Matthew Gentzkow. 2010. Persuasion: Empirical evidence. Annual Review of Economics 2 (1): 643-69. doi:10.1146/annurev.economics.102308.124309.

Deschênes, Olivier, and Michael Greenstone. 2007. The economic impacts of climate change: Evidence from agricultural output and random fluctuations in weather. American Economic Review 97 (1): 354-85.

-- - 2011. Climate change, mortality, and adaptation: Evidence from annual fluctuations in weather in the US. American Economic Journal: Applied Economics 3 (4): 152-85.

Doyle, Matthew, Corrado Di Maria, lan A. Lange, and Emiliya Lazarova. 2016. Electoral incentives and firm behavior: Evidence from U.S. power plant pollution abatement. CESifo Working paper series 6127, CESifo Group Munich.

Druckman, James N. 2004. Political preference formation: Competition, deliberation, and the (ir)relevance of framing effects. American Political Science Review 98 (4): 671-86. doi:10.1017/S0003055404041413. 
Druckman, James N., Erik Peterson, and Rune Slothuus. 2013. How elite partisan polarization affects public opinion formation. American Political Science Review 107 (1): 57-79. doi:10.1017/S0003055412000500.

Dunlap, Riley E., and Aaron M. McCright. 2008. A widening gap: Republican and Democratic views on climate change. Environment: Science and Policy for Sustainable Development 50 (5): 26-35. doi:10.3200/ENVT.50.5.26-35.

Egan, Patrick J., and Megan Mullin. 2017. Climate change: US public opinion. Annual Review of Political Science 20 (1): 209-27. doi:10.1146/annurev-polisci-051215-022857.

Eggers, Andrew C., Anthony Fowler, Jens Hainmueller, Andrew B. Hall, and James M. Snyder. 2015. On the validity of the regression discontinuity design for estimating electoral effects: New evidence from over 40,000 close races. American Journal of Political Science 59 (1): 259-74. doi:10.1111/ajps.12127.

Elsasser, Shaun W., and Riley E. Dunlap. 2013. Leading voices in the denier choir: Conservative columnists' dismissal of global warming and denigration of climate science. American Behavioral Scientist 57 (6): 754-76. doi:10.1177/0002764212469800.

Evans, John H. 2003. Have Americans' attitudes become more polarized? An update. Social Science Quarterly 84 (1): 71-90. doi:10.1111/1540-6237.8401005.

Ferreira, Fernando, and Joseph Gyourko. 2009. Do political parties matter? Evidence from U.S. cities. Quarterly Journal of Economics 124 (1): 399-422. doi:10.1162/qjec.2009.124.1.399.

Fisher, Anthony, W. Michael Hanemann, Michael Roberts, and Wolfram Schlenker. 2012. The economic impacts of climate change: Evidence from agricultural output and random fluctuations in weather; Comment. American Economic Review 102 (7): 3749-60.

Gabel, Matthew, and Kenneth Scheve. 2007. Estimating the effect of elite communications on public opinion using instrumental variables. American Journal of Political Science 51 (4): 1013-28. doi:10.1111/j.15405907.2007.00294.x.

Gallup. 2016. U.S. concern about global warming at eight-year high (March 16). http://news.gallup.com/poll/190010/concern-global-warming-eight-year-high.aspx.

Gelman, Andrew, and Guido Imbens. 2017. Why high-order polynomials should not be used in regression discontinuity designs. Journal of Business and Economic Statistics. doi:10.1080/07350015.2017.1366909.

Gerber, Alan S., James G. Gimpel, Donald P. Green, and Daron R. Shaw. 2011. How large and long-lasting are the persuasive effects of televised campaign ads? Results from a randomized field experiment. American Political Science Review 105 (1): 135-50.

Gerber, Alan S., Dean Karlan, and Daniel Bergan. 2009. Does the media matter? A field experiment measuring the effect of newspapers on voting behavior and political opinions. American Economic Journal: Applied Economics 1 (2): 35-52.

Graff Zivin, Joshua, Solomon M. Hsiang, and Matthew Neidell. 2018. Temperature and human capital in the short and long run. Journal of the Association of Environmental and Resource Economists 5 (1): 77-105. doi:10.1086/694177.

Grimmer, Justin, Eitan Hersh, Brian Feinstein, and Daniel Carpenter. 2011. Are close elections random? Unpublished manuscript, Department of Political Science, Stanford University.

Gromet, Dena M., Howard Kunreuther, and Richard P. Larrick. 2013. Political ideology affects energy-efficiency attitudes and choices. Proceedings of the National Academy of Science USA 110 (23): 9314.

Guber, Deborah Lynn. 2013. A cooling climate for change? Party polarization and the politics of global warming. American Behavioral Scientist 57 (1): 93-115. doi:10.1177/0002764212463361.

Hardisty, David J., Eric J. Johnson, and Elke U. Weber. 2010. A dirty word or a dirty world? Attribute framing, political affiliation, and query theory. Psychological Science 21 (1): 86-92. doi:10.1177/0956797609355572.

Hetherington, Marc J. 2001. Resurgent mass partisanship: The role of elite polarization. American Political Science Review 95 (3): 619-31. 
Hinckley, Barbara, Richard Hofstetter, and John Kessel. 1974. Information and the vote: A comparative election study. American Politics Quarterly 2 (2): 131-58. doi:10.1177/1532673X7400200201.

Hornsey, Matthew J., Emily A. Harris, Paul G. Bain, and Kelly S. Fielding. 2016. Meta-analyses of the determinants and outcomes of belief in climate change. Nature Climate Change 6:622.

Howard, Peter, and Derek Sylvan. 2015. Expert consensus on the economics of climate change. Institute for Policy Integrity, New York University School of Law.

Imbens, Guido, and Karthik Kalyanaraman. 2012. Optimal bandwidth choice for the regression discontinuity estimator. Review of Economic Studies 79 (3): 933-59. doi:10.1093/restud/rdr043.

IPCC (Intergovernmental Panel on Climate Change). 2014. Climate change 2014: Synthesis report. Contribution of Working Groups I, II and III to the Fifth Assessment Report of the Intergovernmental Panel on Climate Change (Core writing team, R. K. Pachauri and L. A. Meyer, eds.). IPCC, Geneva.

Jacobsen, Grant D. 2011. The Al Gore effect: An inconvenient truth and voluntary carbon offsets. Journal of Environmental Economics and Management 61 (1): 67-78. doi:10.1016/j.jeem.2010.08.002.

Jacques, Peter J., Riley E. Dunlap, and Mark Freeman. 2008. The organisation of denial: Conservative think tanks and environmental scepticism. Environmental Politics 17 (3): 349-85. doi:10.1080/09644010802055576.

Kahan, Dan M. 2015. Climate-science communication and the measurement problem. Political Psychology 36:143. doi:10.1111/pops.12244.

Kahn, Matthew E. 2007. Do Greens drive hummers or hybrids? Environmental ideology as a determinant of consumer choice. Journal of Environmental Economics and Management 54 (2): 129-45. doi:10.1016/j.jeem.2007.05.001.

Kahn, Matthew E., and Daxuan Zhao. 2017. The impact of climate change skepticism on adaptation in a market economy. NBER Working paper, National Bureau of Economic Research, Cambridge, MA.

Kam, Cindy D. 2005. Who toes the party line? Cues, values, and individual differences. Political Behavior 27 (2): 163-82.

Koronowski, Ryan. 2014. The climate guide to governors. https://thinkprogress.org/the-climate-guide-togovernors-a822a998a94a/.

Kousser, Thad, and Bruce Tranter. 2018. The influence of political leaders on climate change attitudes. Global Environmental Change 50:100-109. doi:10.1016/j.gloenvcha.2018.03.005.

Lee, David S. 2001. The electoral advantage to incumbency and voters' valuation of politicians' experience: A regression discontinuity analysis of elections to the U.S House. NBER Working paper 8441, National Bureau of Economic Research, Cambridge, MA.

- - . 2008. Randomized experiments from non-random selection in U.S. House elections. Journal of Econometrics 142 (2): 675-97. doi:10.1016/j.jeconom.2007.05.004.

Lee, David S., and Thomas Lemieux. 2010. Regression discontinuity designs in economics. Journal of Economic Literature 48 (2): 281-355.

Lee, David, S., Enrico Moretti, and Matthew J. Butler. 2004. Do voters affect or elect policies? Evidence from the U.S. House. Quarterly Journal of Economics 119 (3): 807-59. doi:10.1162/0033553041502153.

Leigh, Andrew. 2008. Estimating the impact of gubernatorial partisanship on policy settings and economic outcomes: A regression discontinuity approach. European Journal of Political Economy 24 (1): 256-68. doi:10.1016/j.ejpoleco.2007.06.003.

Leip, David. 2017. Dave Leip's atlas of US presidential elections. https://uselectionatlas.org/.

Lenz, Gabriel. 2009. Learning and opinion change, not priming: Reconsidering the priming hypothesis. American Journal of Political Science 53 (4): 821-37.

Levendusky, Matthew S. 2010. Clearer cues, more consistent voters: A benefit of elite polarization. Political Behavior 32 (1): 111-31.

Malka, Ariel, Jon A. Krosnick, and Gary Langer. 2009. The association of knowledge with concern about global warming: Trusted information sources shape public thinking. Risk Analysis 29 (5): 633-47. doi:10.1111/j.1539-6924.2009.01220.x. 
McCrary, Justin. 2008. Manipulation of the running variable in the regression discontinuity design: A density test. Journal of Econometrics 142 (2): 698-714.

McCright, Aaron M., and Riley E. Dunlap. 2003. Defeating Kyoto: The conservative movement's impact on U.S. climate change policy. Social Problems 50 (3): 348-73. doi:10.1525/sp.2003.50.3.348.

- - . 2011. The politicization of climate change and polarization in the American public's views of global warming, 2001-2010. Sociological Quarterly 52 (2): 155-94. doi:10.1111/j.1533-8525.2011.01198.x.

Millner, Antony, and Hélène Ollivier. 2016. Beliefs, politics, and environmental policy. Review of Environmental Economics and Policy 10 (2): 226-44. doi:10.1093/reep/rew010.

Pettersson-Lidbom, Per. 2008. Do parties matter for economic outcomes? A regression-discontinuity approach. Journal of the European Economic Association 6 (5): 1037-56. doi:10.1162/JEEA.2008.6.5.1037.

Pew Research Center. 2016. The politics of climate (October). https://www.pewresearch.org/science/2016/10/04/the-politics-of-climate/.

Rabe, Barry, and Christopher Borick. 2017. National surveys on energy and environment (United States). Interuniversity Consortium for Political and Social Research, Ann Arbor, MI (distributor), 2017-07-14. doi:10.3886/E100167V12.

Rugeley, Cynthia R., and John David Gerlach. 2012. Understanding environmental public opinion by dimension: How heuristic processing mitigates high information costs on complex issues. Politics and Policy 40 (3): 444-70. doi:10.1111/j.1747-1346.2012.00352.x.

Schlenker, Wolfram, and Michael J. Roberts. 2009. Nonlinear temperature effects indicate severe damages to U.S. crop yields under climate change. Proceedings of the National Academy of Sciences 106 (37): 15594-98. doi:10.1073/pnas.0906865106.

Shapiro, Jesse M. 2016. Special interests and the media: Theory and an application to climate change. Journal of Public Economics 144:91-108. doi:10.1016/j.jpubeco.2016.10.004.

Sinha, Paramita, Martha L. Caulkins, and Maureen L. Cropper. 2018. Household location decisions and the value of climate amenities. Journal of Environmental Economics and Management 92:608-37. doi:10.1016/j.jeem.2017.08.005.

Skovron, Christopher, and Rocio Titiunik. 2015. A practical guide to regression discontinuity designs in political science. Unpublished manuscript, Department of Political Science, University of Michigan.

Snyder, J. 2005. Detecting manipulation in US House elections. Unpublished manuscript, Haas School of Business, University of California Berkeley.

Squire, Peverill, and Christina Fastnow. 1994. Comparing gubernatorial and senatorial elections. Political Research Quarterly 47 (3): 705-20. doi:10.1177/106591299404700308.

Tol, Richard S. J. 2018. The economic impacts of climate change. Review of Environmental Economics and Policy 12 (1): 4-25. doi:10.1093/reep/rex027.

US Census. 2016. Quick facts. https://www.census.gov/quickfacts/fact/table/US/PST045216.

$\mathrm{Yu}$, Zhihao. 2005. Environmental protection: A theory of direct and indirect competition for political influence. Review of Economic Studies 72 (1): 269-86.

Zaller, John R. 1992. The nature and origins of mass opinion. Cambridge Studies in Public Opinion and Political Psychology. Cambridge: Cambridge University Press. doi:10.1017/CBO9780511818691. 